\title{
Runup and rundown generated by three-dimensional sliding masses
}

\author{
By P. L.-F. LIU ${ }^{1}$, T.-R. W U ${ }^{1}$, F. RAICHLEN ${ }^{2}$, \\ C. E. SYNOLAKIS AND J. C. BORRERO \\ ${ }^{1}$ School of Civil and Environmental Engineering, Cornell University, Ithaca, NY 14853, USA \\ ${ }^{2}$ Division of Engineering and Applied Sciences, California Institute of Technology, \\ Pasadena, CA 91108, USA \\ ${ }^{3}$ Department of Civil and Environmental Engineering, University of Southern California, \\ Los Angeles, CA 90089, USA
}

(Received 11 May 2004 and in revised form December 13, 2004)

To study the waves and runup/rundown generated by a sliding mass, a numerical simulation model, based on the large-eddy-simulation (LES) approach, was developed. The Smagorinsky subgrid scale model was employed to provide turbulence dissipation and the volume of fluid (VOF) method was used to track the free surface and shoreline movements. A numerical algorithm for describing the motion of the sliding mass was also implemented.

To validate the numerical model, we conducted a set of large-scale experiments in a wave tank of $104 \mathrm{~m}$ long, $3.7 \mathrm{~m}$ wide and $4.6 \mathrm{~m}$ deep with a plane slope (1:2) located at one end of the tank. A freely sliding wedge with two orientations and a hemisphere were used to represent landslides. Their initial positions ranged from totally aerial to fully submerged, and the slide mass was also varied over a wide range. The slides were instrumented to provide position and velocity time histories. The time-histories of water surface and the runup at a number of locations were measured.

Comparisons between the numerical results and experimental data are presented only for wedge shape slides. Very good agreement is shown for the time histories of runup and generated waves. The detailed three-dimensional complex flow patterns, free surface and shoreline deformations are further illustrated by the numerical results. The maximum runup heights are presented as a function of the initial elevation and the specific weight of the slide. The effects of the wave tank width on the maximum runup are also discussed.

\section{Introduction}

Tsunamis are long water waves generated by impulsive geophysical events of the seafloor, volcanoes, asteroid impacts and landslides. While the mechanism for generating the initial water waves by purely tectonic motions is reasonably well understood, the modelling of tsunamis generated by submarine landslides is not (Synolakis et al. 1997; Bardet et al. 2003). Co-seismic deformation of the seafloor usually occurs rapidly relative to the propagation speeds of long water waves, allowing for simple specification of initial conditions by transferring the resultant permanent seafloor deformation to the free surface. However, subaerial and submarine landslides move less rapidly and the time-history of seafloor deformation is important, necessitating the addition of source terms in the equations of motions (e.g. Liu, Lynnet \& Synolakis 2003). 
Compared with the understanding of earthquake-induced initial tsunami waves, the understanding of landslide-generated waves is marginal. Earlier studies have been summarized in Synolakis (2003). Briefly, in terms of the semi-analytical empirical studies, based on the work of Stirem \& Miloh (1975), Murty (1979) transferred the energy released by a moving block sliding from its initial position to its final position to solitary waves and calculated the height of the wave. Pelinovsky \& Poplavsky (1996), and later Watts (1997), presented the force balance on a submerged solid body sliding down an incline and calculated the terminal velocity. Few computational methods exist to generate one- or two-dimensional water surfaces generated by underwater mass movements (Heinrich 1992; Jiang \& LeBlond 1992; Grilli, Watts \& Dias 2001; Ward 2001; Liu et al. 2003; Yuk, Yim \& Liu 2003), and with few exceptions, the methods have not been carefully validated with comparison with laboratory data, because data at appropriate scales to allow dynamic similitude did not exist.

In terms of laboratory studies, Wiegel (1955) described impulsively generated water waves as: 'the sudden movement of a submerged body for a short interval of time, which may be considered representative of a submarine landslide.' He stated that the energy in the wave generated by a submerged falling block is of order $1 \%$ of the initial potential energy of the block. Wiegel (1955) considered both vertically falling blocks and blocks sliding down an inclined plane. His data suggest that wave height increases with increasing slope, submerged weight and decreasing depth of submergence and that wave period increases with decreasing slope. Watts (1997) performed a series of two-dimensional small-scale experiments with sliding blocks and granular masses, but did not measure runup.

In an effort to understand better the generation and runup of waves from submarine and subaerial slides, we conducted 'small-scale' exploratory experiments in a glasswalled wave tank $38 \mathrm{~cm}$ wide and $61 \mathrm{~cm}$ deep with a plane beach sloped 1 vertical to 2.08 horizontal constructed of precision aluminium plate representing the nearshore region. These experiments used a triangular-shaped lead block to represent a landslide. The dimensions of the triangular cross-section were: horizontal length $b=18 \mathrm{~cm}$, vertical front-face height $a=9 \mathrm{~cm}$, and width (thickness) $w=5 \mathrm{~cm}$. A Teflon membrane affixed to the base in contact with the slope reduced the effects of friction. The horizontal surface of the wedge was initially positioned either a small distance above or below the still water level to represent a subaerial or a submarine landslide. The block was released from rest, abruptly moving down-slope under the effect of gravity. Water surface-time histories were obtained in front of the at-rest position of the wedge and to one side. In this case, only offshore and nearshore laterally propagating waves were measured. Because of the small scale, the runup was not measured.

An example of the waves measured a relative distance $x / b=4.26$ seaward of the shoreline and on the centreline for two cases are presented in figure 1. The abscissa is the time relative to the first maximum and the ordinate is the measured wave amplitude. The top surface of the wedge, when representing a submarine landslide, was initially $1.5 \mathrm{~cm}$ below the still water level (SWL); for a subaerial landslide, the top surface of the wedge was $1.4 \mathrm{~cm}$ above the SWL.

We note that the amplitude of the seaward generated wave is relatively small, with the first positive wave about $50 \%$ larger for the subaerial case compared to the submerged slide. If we consider the front face of the wedge as being the wave generator for the first positive offshore propagating wave associated with its initial motion, the height of the vertical face of the 'generator' for the subaerial landslide is $15 \%$ less than for the submerged case. Considering only these dimensions, we would 


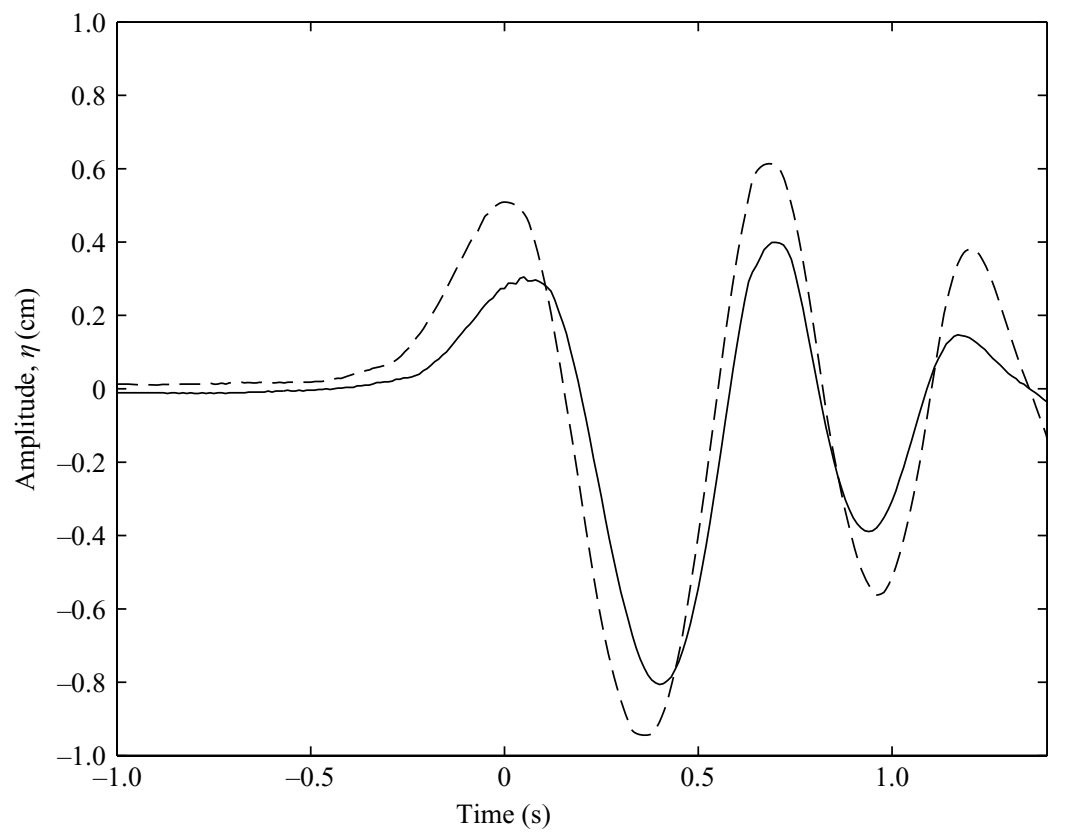

FIGURE 1. Time histories of the free-surface fluctuations at $x / b=4.26$ seaward of the shoreline on the centreline for - , submerged and ---, subaerial slides in the small-scale experiment.

expect the wave from the subaerial landslide to be less than that from the submarine landslide, which is not the case as seen in figure 1 . Therefore, the difference in the wave heights, to a large extent, must be due to the characteristics of the initial wedge motion. For the subaerial landslide, the initial acceleration would be larger than that for the submerged wedge owing to larger inertial and viscous effects for the latter (this will be discussed more fully later).

The magnitude of the waves in figure 1 underscores the need for experiments at a larger size to reduce scale effects and to study the three-dimensional problem. Only from such experiments can the water surface time history in the region of generation and the time history of runup be defined at a large enough scale so that a reliable data base can be realized. Such data are urgently needed to confirm (or refute), with confidence, numerical models of coastal inundation limits and runup that are in various stages of development. In the study presented herein, we have concentrated primarily on the question of runup and rundown of three-dimensional sliding bodies both submerged and subaerial.

Since only a limited number of physical variables can be measured, it is difficult to appreciate and understand the complex flow field generated by a sliding mass with the experimental data alone. Therefore, we have also developed a three-dimensional large-eddy simulation (LES) model. The Smagorinsky subgrid-scale (SGS) model is used with a filter width that is directly correlated to the grid-lengths for the finite volume discretization of the flow domain. The volume of fluid (VOF) method similar to Kothe et al. (1999) and Rider \& Kothe (1998) is employed to track the free surface and shoreline movement. To simulate the movement of a slide, a numerical algorithm similar to Heinrich $(1991,1992)$ is implemented for three-dimensional slides. In this paper, results from 45 computational simulations for the wedge-shaped slide with a vertical front face are shown and discussed. Both submerged and subaerial slides 
with different specific weights are included. Experimental data for time histories of free-surface fluctuations and the runup/rundown at various locations are used to check the numerical results. The computationally simulated results are then used to illustrate the complex three-dimensional flow patterns in terms of the velocity field, shoreline evolution and free-surface profiles. The effects of wave-tank width on the maximum runup are also discussed.

\section{The computational model}

\subsection{The large-eddy simulation}

The description of flow motions generated by a slide movement can be obtained by solving the Navier-Stokes equations with appropriate initial and boundary conditions. However, the size of the physical domain of a land slide is usually too large to employ the direct numerical simulation (DNS). Therefore, the LES approach (Deardorff 1970), which solves the large-scale eddy motions and models the small-scale turbulent fluctuations, becomes an attractive alternative. In the LES approach, a spatial filter is applied to the Navier-Stokes equations and the resulting filtered equations of motions read:

$$
\begin{gathered}
\frac{\partial\left\langle u_{i}\right\rangle}{\partial x_{i}}=0, \\
\frac{\partial\left\langle u_{i}\right\rangle}{\partial t}+\frac{\partial\left\langle u_{i} u_{j}\right\rangle}{\partial x_{j}}=-\frac{1}{\rho} \frac{\partial\langle p\rangle}{\partial x_{i}}+\rho g_{i}+\frac{1}{\rho} \frac{\partial\left\langle\tau_{i j}\right\rangle}{\partial x_{j}},
\end{gathered}
$$

in which $i, j=1,2,3,\left\langle u_{i}\right\rangle$ and $\langle p\rangle$ are the filtered velocity and pressure, respectively. $\left\langle\tau_{i j}\right\rangle$ is the viscous stress of the filtered velocity field, $\rho$ is the fluid density, and $g_{i}$ is the acceleration due to gravity. The filtered momentum flux, $\rho\left\langle u_{i} u_{j}\right\rangle$, is different from the flux of filtered momentum, $\rho\left\langle u_{i}\right\rangle\left\langle u_{j}\right\rangle$. The difference is the residual-stress tensor, or the SGS Reynolds stress:

$$
\left\langle\tau_{i j}^{R}\right\rangle=-\rho\left(\left\langle u_{i} u_{j}\right\rangle-\left\langle u_{i}\right\rangle\left\langle u_{j}\right\rangle\right)
$$

While the residual kinetic energy is defined as

$$
k_{r}=\frac{1}{2}\left\langle\tau_{i i}^{R}\right\rangle,
$$

the anisotropic residual-stress tensor component can be defined as

$$
\left\langle\tau_{i j}^{r}\right\rangle=\left\langle\tau_{i j}^{R}\right\rangle-\frac{2}{3} k_{r} \delta_{i j} .
$$

Consequently, the isotropic residual-stress tensor component can be absorbed in the modified filtered pressure field

$$
\langle P\rangle=\langle p\rangle+\frac{2}{3} k_{r} .
$$

Substituting (2.3)-(2.6) into (2.2), the filtered momentum equation can be rewritten as

$$
\frac{\partial\left\langle u_{i}\right\rangle}{\partial t}+\frac{\partial\left\langle u_{i}\right\rangle\left\langle u_{j}\right\rangle}{\partial x_{j}}=-\frac{1}{\rho} \frac{\partial\langle P\rangle}{\partial x_{i}}+g_{i}+\frac{1}{\rho} \frac{\partial\left\langle\tau_{i j}\right\rangle}{\partial x_{j}}+\frac{1}{\rho} \frac{\partial\left\langle\tau_{i j}^{r}\right\rangle}{\partial x_{j}} .
$$

In the momentum equation, the viscous stress is linearly proportional to the strain tensor of the filtered velocity field,

$$
\left\langle\tau_{i j}\right\rangle=\mu\left(\frac{\partial\left\langle u_{i}\right\rangle}{\partial x_{j}}+\frac{\partial\left\langle u_{j}\right\rangle}{\partial x_{i}}\right)=2 \mu\left\langle S_{i j}\right\rangle,
$$


where $\mu$ is the molecular viscosity of the fluid and $\left\langle S_{i j}\right\rangle$ is the strain tensor. Similarly, the Smagorinsky SGS model also assumes that the SGS Reynolds stress is linearly proportional the strain tensor (Smagorinsky 1963),

$$
\left\langle\tau_{i j}^{r}\right\rangle=\mu_{t}\left(\frac{\partial\left\langle u_{i}\right\rangle}{\partial x_{j}}+\frac{\partial\left\langle u_{j}\right\rangle}{\partial x_{i}}\right)=2 \mu_{t}\left\langle S_{i j}\right\rangle,
$$

in which $\mu_{t}$ represents the SGS eddy viscosity of the residual motions. The SGS eddy viscosity is modelled as

$$
\mu_{t}=\rho\left(C_{s} W\right)^{2}\left(2\left\langle S_{i j}\right\rangle\left\langle S_{i j}\right\rangle\right)^{1 / 2},
$$

where $\left(C_{s} W\right)$ denotes the Smagorinsky length scale and is the product of the Smagorinsky coefficient $C_{s}$ and the filter width $W$. In the finite-volume discretization, which is used in the present model, the filter width, $W$, is the grid size:

$$
W=\left(\Delta x_{1} \Delta x_{2} \Delta x_{3}\right)^{1 / 3},
$$

where $\Delta x_{i}, i=1,2,3$ are the three components of the grid lengths. Under the isotropic turbulence condition, the Smagorinsky coefficient $C_{s} \sim 0.2$. However, $C_{s}$ is usually not a constant; its value may vary from 0.1 to 0.2 for different flows. The present simulations have used a value of 0.15 as suggested by previous work for wavestructure interactions (Lin \& Li 2003). We remark here that existing papers have also suggested that the Smagorinsky SGS model must be modified for the region close to the free surface (i.e. Shen \& Yue 2001). A mixed dynamic SGS model has been developed for complex flows (Dommermuth et al. 2002; Hendrikson et al. 2003). In the present simulations, we have decided to use the Smagorinsky SGS model for its simplicity $\left(C_{s}\right.$ is the only empirical coefficient used in the entire simulation model). The dynamic subgrid model approach will be explored in future work.

The momentum equations of LES with the Smagorinsky SGS model can be expressed as:

$$
\frac{\partial\left\langle u_{i}\right\rangle}{\partial t}+\frac{\partial\left\langle u_{i} u_{j}\right\rangle}{\partial x_{j}}=-\frac{1}{\rho} \frac{\partial\langle P\rangle}{\partial x_{i}}+g_{i}+\frac{1}{\rho} \frac{\partial}{\partial x_{j}}\left[\mu_{\text {eff }}\left(\frac{\partial\left\langle u_{i}\right\rangle}{\partial x_{j}}+\frac{\partial\left\langle u_{j}\right\rangle}{\partial x_{i}}\right)\right],
$$

where $\mu_{e f f}=\mu+\mu_{t}$.

\subsection{Numerical algorithms}

The filtered momentum and continuity equations are solved by using the finite-volume two-step projection method (Bussmann, Kothe \& Sicilian 2002). The forward time difference method is used to discretize the time derivative. To track the free-surface locations, the volume of fluid (VOF) method is used. The VOF method was originally developed by Hirt \& Nichols (1981) and has been improved by Kothe et al. (1999) to second-order accuracy on the free-surface reconstruction. This portion of the present model follows closely the model called Telluride developed by Kothe et al. (1999). New algorithms have been added in order to simulate turbulent free-surface flows generated by a moving slide. The VOF method as well as the moving-boundary algorithm are briefly described as follows.

In order to simulate the free-surface motion on a fixed grid system, a volume of fluid function, $f$, representing the volume fraction of water within a computational cell, is introduced. The value of $f$ is equal to 1 if the cell is full, zero if empty, and $0<f<1$ if the cell contains a portion of the air-water interface. Since $f$ is advected 
by fluid flows, it can be described by:

$$
\frac{\partial f}{\partial t}+\frac{\partial\left\langle u_{i}\right\rangle f}{\partial x_{i}}=0
$$

The momentum equation (2.12) must be modified to be

$$
\frac{\partial f\left\langle u_{i}\right\rangle}{\partial t}+\frac{\partial f\left\langle u_{i} u_{j}\right\rangle}{\partial x_{j}}=-\frac{1}{\rho} \frac{\partial\langle P\rangle}{\partial x_{i}}+f g_{i}+\frac{1}{\rho} \frac{\partial}{\partial x_{j}}\left[\mu_{e f f}\left(\frac{\partial f\left\langle u_{i}\right\rangle}{\partial x_{j}}+\frac{\partial f\left\langle u_{j}\right\rangle}{\partial x_{i}}\right)\right] .
$$

The piecewise linear interface calculation (PLIC) (Rider \& Kothe 1998; Kothe et al. 1999) volume tracking algorithm is used to solve $(2.13)$ for $f$ at the $(n+1)$ th new time step. For details of the numerical scheme, see $\mathrm{Wu}$ (2004).

Consider a cell volume, $V$, containing an object (a portion of the moving slide). The object is defined by its volume $V_{o b j}$ and its surface, $A_{o b j}$. As the slide moves through the flow domain, the object volume will either increase or decrease within the computational cell. The volume of the fluid within the same cell will either decrease or increase correspondingly. Thus, the continuity equation of the fluid flow in the cell with volume, $V$, can be expressed as:

$$
\frac{\partial\left\langle u_{i}\right\rangle}{\partial x_{i}}=\frac{1}{V} \frac{\mathrm{d} V_{o b j}}{\mathrm{~d} t}=\phi\left(x_{i}, t\right)
$$

where $\phi$ denotes the internal source function determined by the rate of change of the object volume within $V$. The momentum equation must also be modified to be:

$$
\frac{\partial f\left\langle u_{i}\right\rangle}{\partial t}+\frac{\partial f\left\langle u_{i} u_{j}\right\rangle}{\partial x_{j}}=-\frac{1}{\rho} \frac{\partial\langle P\rangle}{\partial x_{i}}+f g_{i}+\frac{1}{\rho} \frac{\partial}{\partial x_{j}}\left[\mu_{e f f}\left(\frac{\partial f\left\langle u_{i}\right\rangle}{\partial x_{j}}+\frac{\partial f\left\langle u_{j}\right\rangle}{\partial x_{i}}\right)\right]+f\left\langle u_{i}\right\rangle \phi .
$$

One of the advantages of using the moving solid algorithm is that the grid system need not fit the solid boundary. Therefore, a part of the internal cells will be occupied by the solid material. In order to deal with a cell with partially solid materials and partial fluids, a simple partial cell treatment is applied (Wu 2004).

\subsection{Boundary conditions}

The boundary conditions along solid surfaces are either the no-slip or the no-flux conditions. The pressure within void cells (no fluid) is defined as zero and the velocities are calculated. In the near-wall viscous sublayer region, the largest local turbulent eddy sizes are limited by the viscous scales. Moreover, the turbulence eddies are highly anisotropic. The well-resolved LES model requires grids nearly as fine as those used in DNS. This restriction can be applied not only to the wall-normal direction, but to the streamwise direction. The near-wall resolution requirement clearly limits the application of the LES model to simulating high-Reynolds-number flows. Therefore, a modelling strategy is required to apply the LES to practical applications. Instead of modelling every detail in the near-wall region, this study uses a wall function approach to reduce the number of computational cells. Cabot \& Moin (2000) derived a set of near-wall damping functions and used them to approximate the eddy viscosity at the first cell adjacent to the wall. The eddy viscosity $v_{t}=\mu_{t} / \rho$ is obtained from a Reynolds-averaged Navier-Stokes type mixing-length eddy viscosity model with near-wall damping:

$$
\frac{v_{t}}{v}=\kappa y_{w}^{+}\left(1-\exp \left(-y_{w}^{+} / A\right)\right)^{2}
$$


where $y_{w}^{+}=y_{w} u_{*} / v$ is the distance to the wall in wall units, $\kappa=0.41$ and $A=19$ (Cabot \& Moin 2000). The filtered velocity field is assumed to satisfy the no-slip condition on the wall.

\section{The experiments}

\subsection{Experimental set-up}

We have conducted large-scale experiments in a wave tank at the Oregon State University (OSU) that has a length $104 \mathrm{~m}$, width $3.7 \mathrm{~m}$ and depth $4.6 \mathrm{~m}$. A plane slope (a beach with an inclination of two horizontal to one vertical) was located near one end of the tank and a dissipating beach at the other end. The slope was constructed of $1.9 \mathrm{~cm}$ thick painted plywood supported by a framework composed of $10 \mathrm{~cm} \times 15 \mathrm{~cm}$ by $0.48 \mathrm{~cm}$ aluminium 'I' beams spaced $122 \mathrm{~cm}$ longitudinally and $72 \mathrm{~cm}$ laterally. This rigid unit of beams and plywood was supported in the wave tank on $10 \mathrm{~cm} \times 10 \mathrm{~cm}$ wooden columns spaced $1.22 \mathrm{~m}$ longitudinally and on angle clips mounted to the sidewalls of the tank. For all experiments, the water depth in the wave tank was about $2.44 \mathrm{~m}$.

In our experiments, a wedge and a hemisphere were used to represent the landslide. The wedge-shaped slide has the following dimensions: a length of $b=91.44 \mathrm{~cm}$, a front face $a=45.72 \mathrm{~cm}$ high and a width of $w=65.25 \mathrm{~cm}$. The wedge was constructed of welded aluminium plate $1.27 \mathrm{~cm}$ thick. Two configurations of the wedge on the slope were used: (i) the front face of the wedge vertical (Series A) and (ii) the wedge turned 'end-for-end' so that for this orientation the top and front faces were neither horizontal nor vertical (Series B). Figure 2 shows these two wedge orientations. The hemisphere was $91.44 \mathrm{~cm}$ in diameter constructed also of $1.27 \mathrm{~cm}$ thick aluminium plate. The wedges and the hemisphere were completely filled with water and lead weights were placed inside the slides to vary their mass and, hence, the initial acceleration when released. The initial slide position ranged from subaerial to submerged. A photograph of the wedge slide experiment is displayed in figure 3, showing that a leading positive seaward propagating wave is generated by the sliding wedge after its release and the water surface above the wedge is depressed causing the shoreline to retreat first.

A definition sketch, using the Series A wedge as an example, is presented in figure 4 showing the nomenclature used for the three slides tested. The distance, $x$, is measured seaward from the intersection of the SWL with the slope. The runup, $R$, is measured vertically from the SWL, and $\Delta$ is the vertical distance from the SWL to the highest point on the slide measured positively upward from the SWL. The distance, $\xi$, is measured parallel to the water surface with its origin at the intersection of the most up-slope part of the slide with the slope when the slide is in its at-rest position. The displacement of the slide down the slope, $s$, is measured from the at-rest centre of mass of the slide in a direction parallel to the slope.

The slides move down the slope by gravity rolling on specially designed 'Vee' shaped wheels (with low friction bearings) which ride on aluminium strips with shallow grooves inset into the slope. The wheels for the wedge experiments were supported on axles with bearing composed of oil-impregnated bronze; the hemisphere used ball bearings in contact with the axle, resulting in reduced Coulomb friction. The clearance between the bottom of the slides and the slope was approximately $3 \mathrm{~mm}$. The slide was positioned and held on the slope using a stainless steel cable about $3 \mathrm{~mm}$ in diameter that consists of two sections connected by a wire loop. This loop is cut to release the slide. A second cable connected to the slide is slack as the body travels down the slope. Near the bottom of the slope a 'rubberized horse hair' filled 


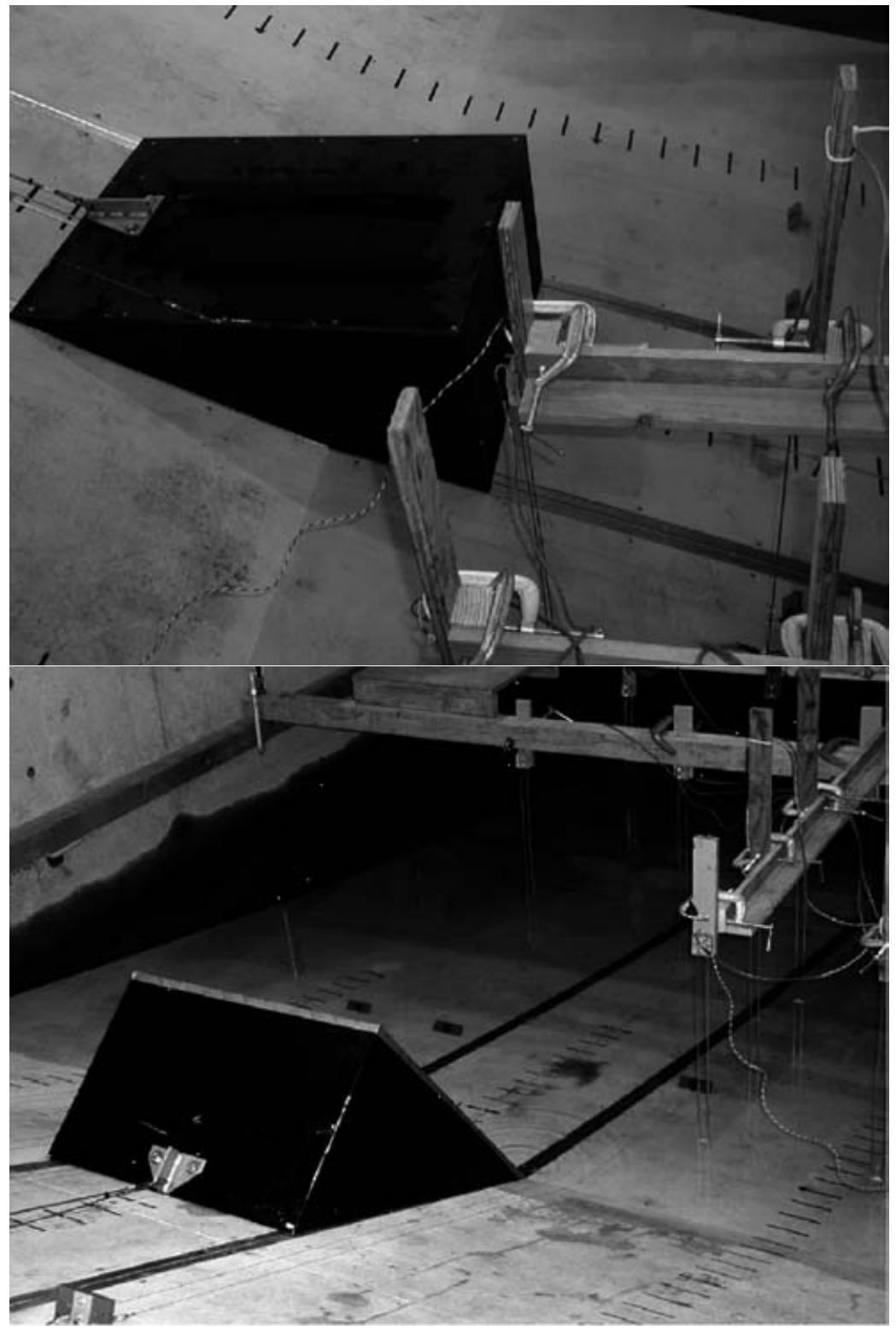

FIGURE 2. Pictures of the wedge used in the experiments.

basket is mounted to the slope to catch the slide before it can run out onto the horizontal bottom of the wave tank. The second cable, mentioned previously, is used with a winch to retrieve the slide and position it for the next experiment. A thin line connects the slide to a rotating potentiometer that provides measurement of the slide's position and velocity time histories.

The runup on the slope was measured in two ways. Video images of the leading edge of the runup tongue were recorded and the maximum runup was estimated visually. In addition to the video imaging method, three resistance wave gauges were installed on the slope to record the time history of the runup. For the wedge slides, the gauge rods were about $1 \mathrm{~mm}$ above the slope, while for the hemisphere slides 


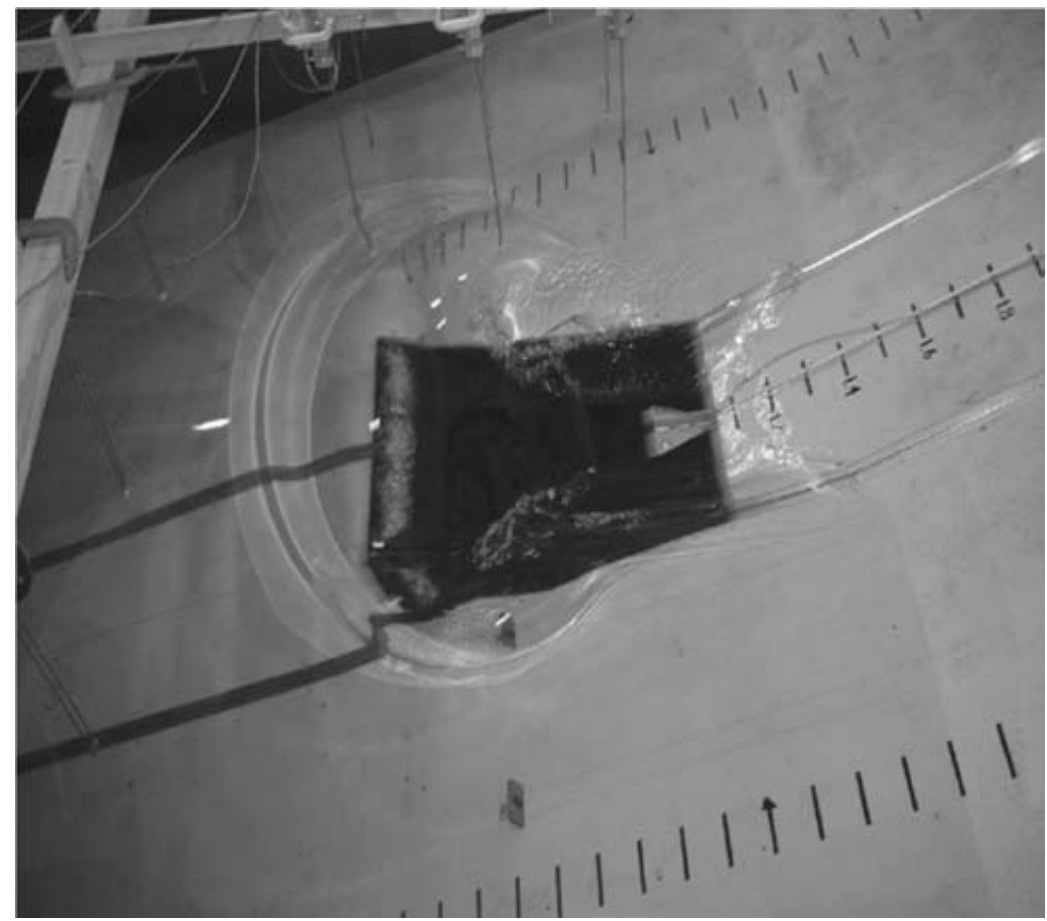

FIGURE 3. A photograph from the large-scale experiments. The leading positive wave is generated by a sliding wedge after its release. The water surface above the wedge is depressed, causing the shoreline to retreat.

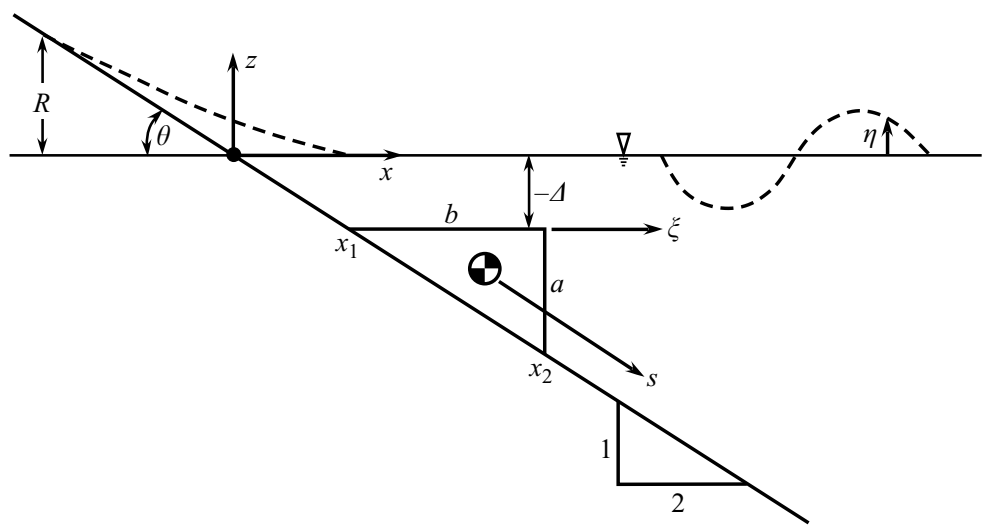

FiguRE 4. A definition sketch for the physical variables employed in this paper.

the arrangement was improved so that the top of the gauge rods was flush with the slope. A sufficient number of wave gauges were used to determine the seaward propagating waves, the waves propagating to either side of the sliding bodies, and for the submerged case, the water surface-time history over the body.

\subsection{Presentation and discussion of experimental results}

An example of the water surface-time histories above a wedge from the Series A experiments is presented in figure 5 for an initial submergence: $\Delta / b=-0.33$, and for 


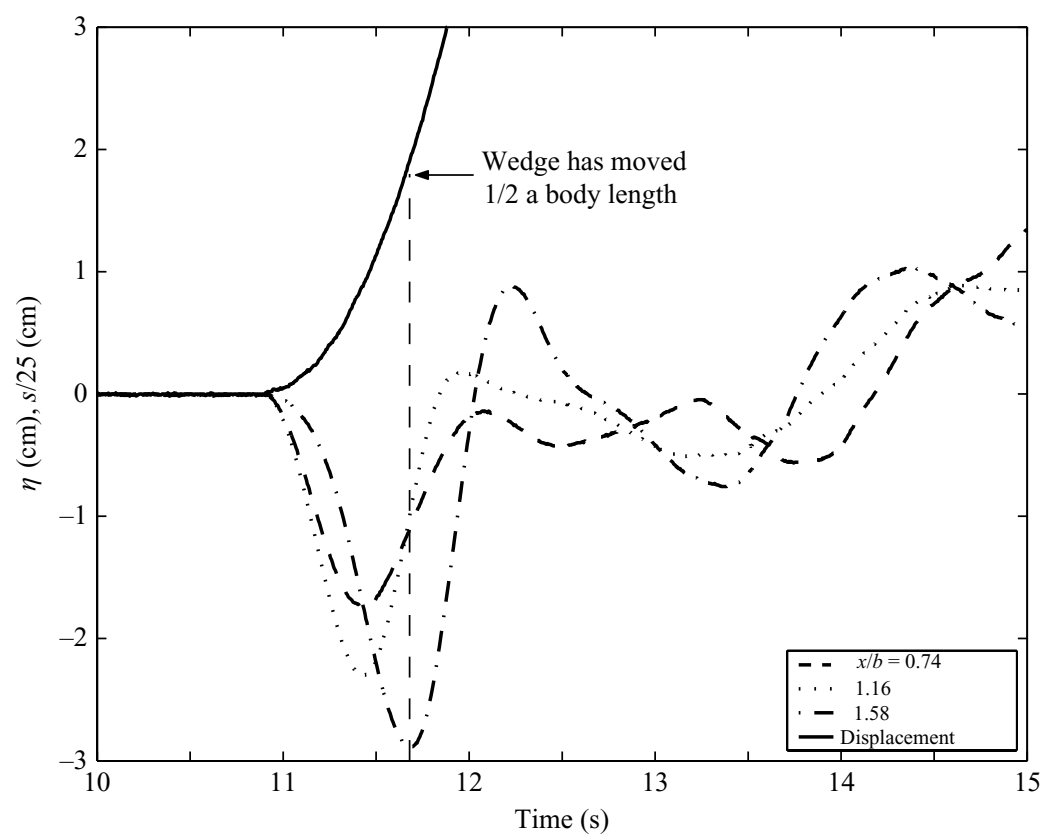

FIGURE 5. Time histories of free surface elevation at three offshore locations along the centreline of the tank. The trajectory of the centre of mass, $s$, along the slope for the wedge is also shown. $\Delta / b=-0.33 ; m=475.5 \mathrm{~kg} ; y / b=0$.

three locations offshore of the SWL shoreline, $x / b$, and on the centreline, $y / b=0$. Also shown in figure 5 is the trajectory (or displacement of the centre of mass, $s$, along the slope) for the $475.5 \mathrm{~kg}$ wedge. The shoreward position of the wedge is $x_{1} / b=0.66$, while the seaward position of the vertical face of the wedge is $x_{2} / b=1.66$. Thus, all three water surface-time histories shown in figure 5 are initially positioned over the slide. As the wedge moves seaward, the water surface above the wedge is initially depressed, reaching a minimum at each location and then rebounding, i.e. moving toward and above the still water level. The maximum depression occurs at the station furthest offshore for which data are available, i.e. $x / b=1.58$, and when the wedge has moved approximately half a body length downslope. The positive disturbance that appears after the depression formed is not the leading positive wave propagating offshore that is generated by the front of the wedge, but it is related to the 'rebound' (see figure 3).

Water surface-time histories over the body on the centreline $(y / b=0.0)$ and to one side $(y / b=0.28)$ for $x / b=1.20$ are presented in figure 6 for a wedge of Series A and for three initial submergences, $\Delta / b$. The Series A wedge in this case has a mass of $475.5 \mathrm{~kg}$, and the lateral edges of the wedge are at $y / b=\mp 0.33$. The origin of time is arbitrary in figure 6 , but it is the same for a given submergence $(\Delta / b)$ and offshore location $(\xi / b)$ for the two lateral locations $(y / b)$. As the initial submergence increases, the wave amplitude of the leading depression wave decreases along with that of the following positive wave. The three-dimensionality of the depression can be seen by comparing the wave on the centreline $(y / b=0)$ and at $y / b=0.28$ for the same submergence. The time lag between the maximum depression on the centreline and at the lateral location is evidence of the lateral propagation speed of the depression wave. 


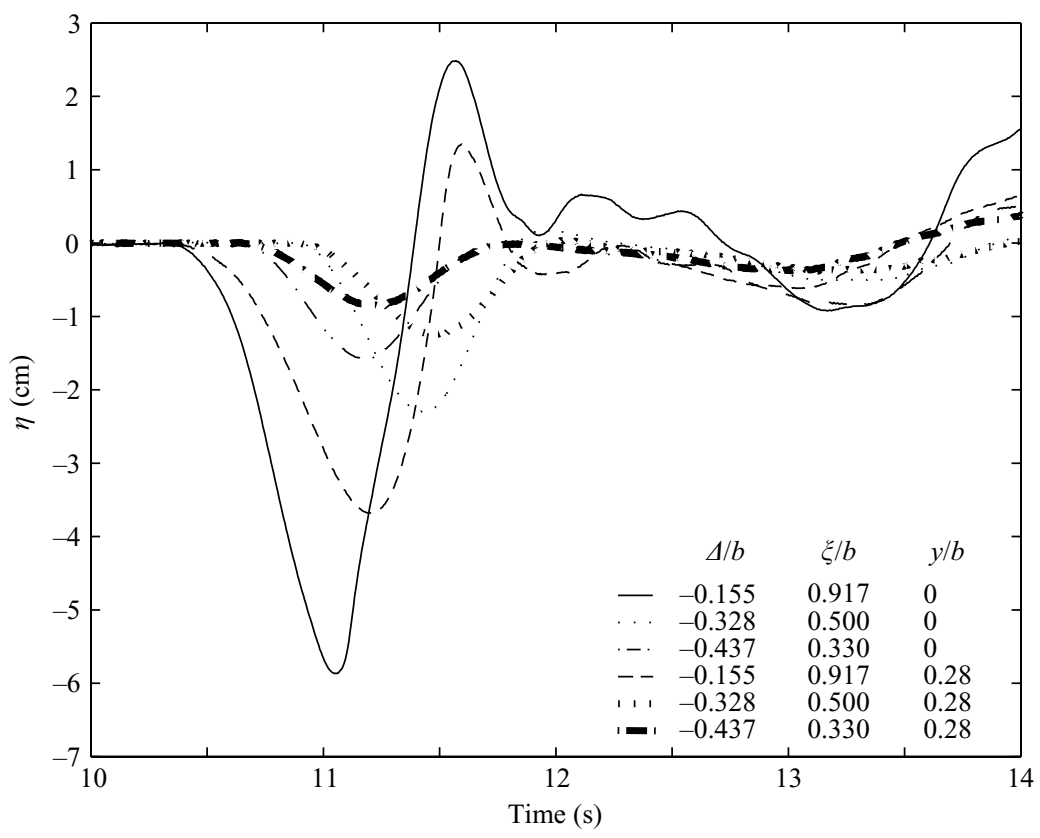

FIGURE 6. Time histories of free-surface elevation at different locations for three initial submergences. $m=475.5 \mathrm{~kg} ; x / b=1.20$.

As mentioned earlier, for the hemisphere experiments, the runup was measured at three lateral locations on the slope using two-wire resistance wave gauges. Each wire was mounted in a recess in the slope so the tops of the wires were flush with the slope. A typical runup measurement is presented in figure 7. In figure 7(a), the runup time history is presented with the runup in $\mathrm{cm}$ plotted as a function of time. In figure $7(b)$, the measured displacement and velocity time histories of the slide movement are shown. The disturbance on the centreline for $0.48 \mathrm{~s}<t<0.9 \mathrm{~s}$ may be caused by the cables that trail behind the slide as it moves downslope. The maximum rundown occurs when the body has moved approximately $100 \mathrm{~cm}$ from its at-rest position (or about one slide length, $b$ ). The rundown is followed by the runup. Figure 7 shows that for this case, the maximum rundown and the maximum runup are each approximately the same at the three lateral locations.

Before pursuing the question of rundown and runup caused by the subaerial and submerged motion of the wedges and hemisphere on the slope, it is useful to discuss the motion of these slides. The equation of motion of a sliding solid body has been given by Pelinovsky \& Poplavsky (1996), and later by Watts (1997) as:

$$
\left(m_{b}+k m_{o}\right) \frac{\mathrm{d}^{2} s}{\mathrm{~d} t^{2}}=\left(m_{b}-m_{o}\right) g\left(\sin \theta-C_{n} \cos \theta\right)-\frac{1}{2} C_{d} \rho A_{p}\left(\frac{\mathrm{d} s}{\mathrm{~d} t}\right)^{2},
$$

where $m_{b}$ is the mass of the body, $m_{o}$ the displaced mass of the body, $k$ the hydrodynamic added mass coefficient, $s$ the displacement of the centre of mass of the body, $g$ the acceleration due to gravity, $\theta$ the angle of the slope relative to the horizontal, $C_{n}$ the Coulomb friction coefficient, $C_{d}$ the drag coefficient of the body, $A_{p}$ the projected area of the body perpendicular to its direction of motion, and $\rho$ the fluid density. 

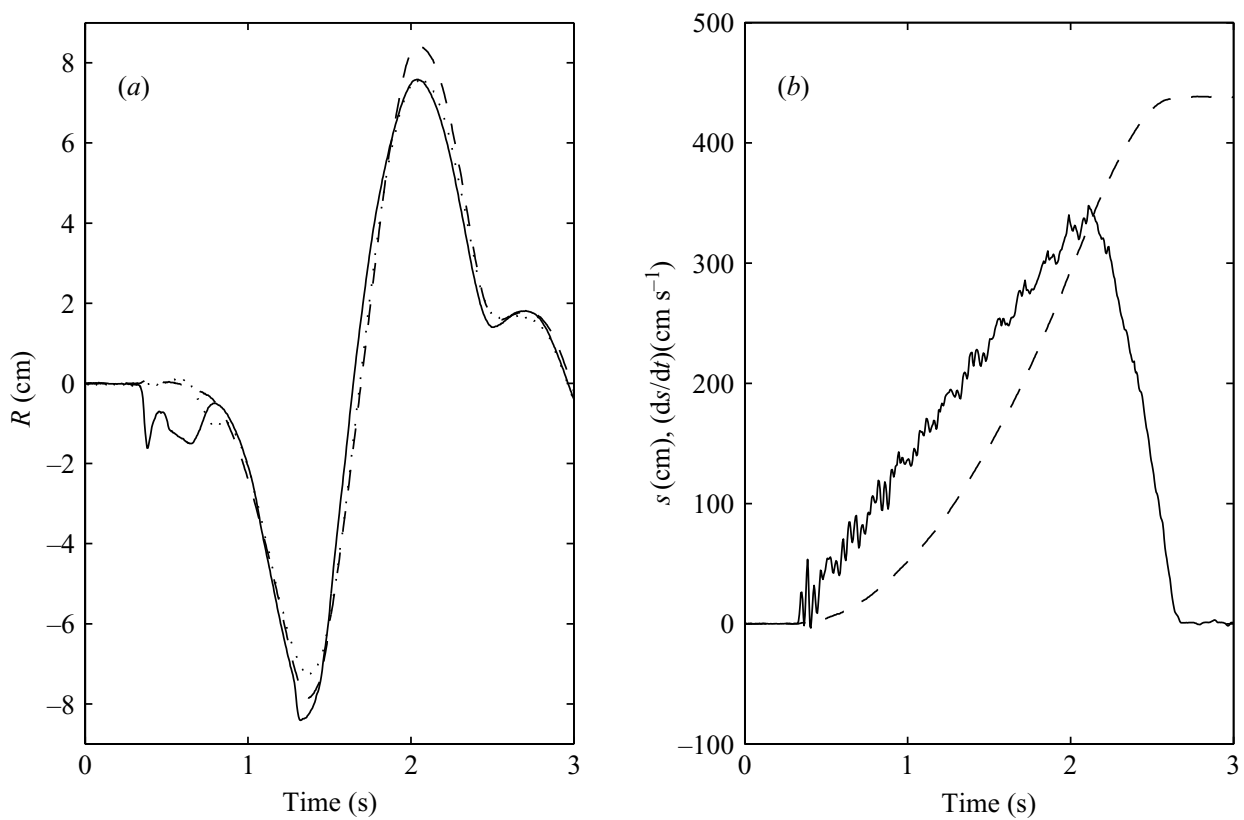

FIgURE 7. (a) The measurements of runup time histories at three different locations for the hemisphere. $\cdots, R$ east;,$- R$ centreline; - -,$R$ west. $(b)$ The corresponding time histories of ---, displacement and -, velocity of the hemisphere.

As will be discussed presently, the initial acceleration, $\left(\mathrm{d}^{2} s / \mathrm{d} t^{2}\right)_{o}$, appears to be an important parameter in defining the rundown and runup caused by a sliding body. For the condition of the initial motion of the body, whether it is subaerial or submerged, the velocity, $\mathrm{d} s / \mathrm{d} t$, would be zero. Thus, (3.1) reduces to:

$$
\frac{\left(\mathrm{d}^{2} s / \mathrm{d} t^{2}\right)_{o}}{g}=\frac{m_{b} / m_{o}-1}{m_{b} / m_{o}+k}\left(\sin \theta-C_{n} \cos \theta\right) .
$$

The initial acceleration was determined by a linear fit to the initial velocity time histories. The initial acceleration determined in this way is shown in figure 8 as a function of the relative submergence, $\Delta / b$, where positive $\Delta$ refers to subaerial slides above the SWL and negative $\Delta$ refers to submarine slides. The data shown correspond to the wedge experiments, Series A and Series B, and the hemisphere experiments. For the subaerial experiments, the data corresponding to the maximum $\Delta / b$ are for cases where the downslope extremity of the slide (the wedges or the hemisphere) just touches the water surface. Therefore, at the time of release for this subaerial location, the displaced mass of the water, $m_{o}$, is zero, and (3.2) reduces to:

$$
\frac{\left(\mathrm{d}^{2} s / \mathrm{d} t^{2}\right)_{o}}{g}=\left(\sin \theta-C_{n} \cos \theta\right) .
$$

Thus, knowing the angle of the slope and by measuring the initial acceleration, the Coulomb friction coefficient, $C_{n}$, could be obtained easily. In figure 8 , a line is shown denoted as $\sin \theta$, and the distance from this line to the data corresponding, for a particular slide, to the maximum $\Delta / b$ is the ratio: $\alpha=F_{\text {Coulomb }} / m_{b} g$. From $\alpha$, the Coulomb friction coefficient, $C_{n}$ can be evaluated for each slide and slide mass. The fact that $\alpha$ varies significantly for the wedges, Series A and B, as the mass 


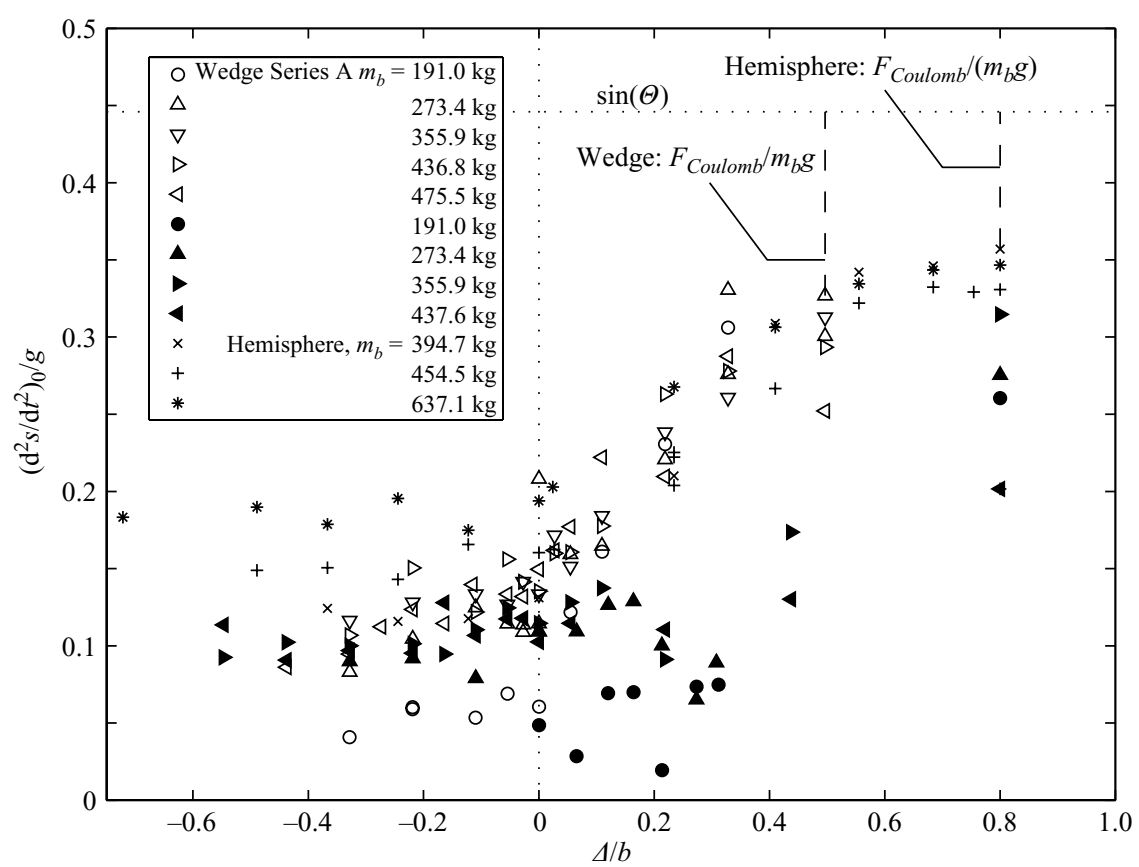

FIGURE 8. The normalized initial acceleration is shown as a function of the relative submergence, $\Delta / b$, where positive $\Delta$ refers to subaerial slides and negative $\Delta$ refers to submarine slides.

\begin{tabular}{|c|c|c|c|c|c|}
\hline \multicolumn{2}{|c|}{ Wedge A } & \multicolumn{2}{|c|}{ Wedge B } & \multicolumn{2}{|c|}{ Hemisphere } \\
\hline Mass (kg) & $C_{n}$ & Mass (kg) & $C_{n}$ & Mass $(\mathrm{kg})$ & $C_{n}$ \\
\hline 190.96 & 0.1577 & 273.44 & 0.1921 & 394.73 & 0.1009 \\
\hline 273.44 & 0.1640 & 355.92 & 0.1482 & 454.44 & 0.1302 \\
\hline 355.92 & 0.1503 & 437.57 & 0.2746 & 637.08 & 0.1125 \\
\hline 436.75 & 0.1720 & & & & \\
\hline 475.52 & 0.2182 & & & & \\
\hline
\end{tabular}

TABlE 1. The Coulomb friction coefficient, $C_{n}$, as a function of series and body mass.

changes and only a small amount for the various hemisphere cases may be due to the less efficient axle bearings used in the wedge experiments compared to those in the hemisphere. The values of the Coulomb friction coefficients, $C_{n}$, are presented in table 1 for the different experiments. For the wedges, the average Coulomb friction coefficient is larger for Series B than for Series A, and it is about half of these values for the hemisphere. As alluded to earlier, these difference are probably due both to the weight placement and the bearings used for the wedges compared to the hemisphere. This may also be due to peculiarities in the wheel orientation and internal weight placement when the wedge is turned end-for-end. (It should be emphasized that $C_{n}$ is determined from the initial acceleration for the body released out of the water; thus, hydrodynamic effects are not present.)

Turning our attention to the runup and rundown produced on the slope by the sliding bodies, the following functional relation describing this runup (or rundown) 


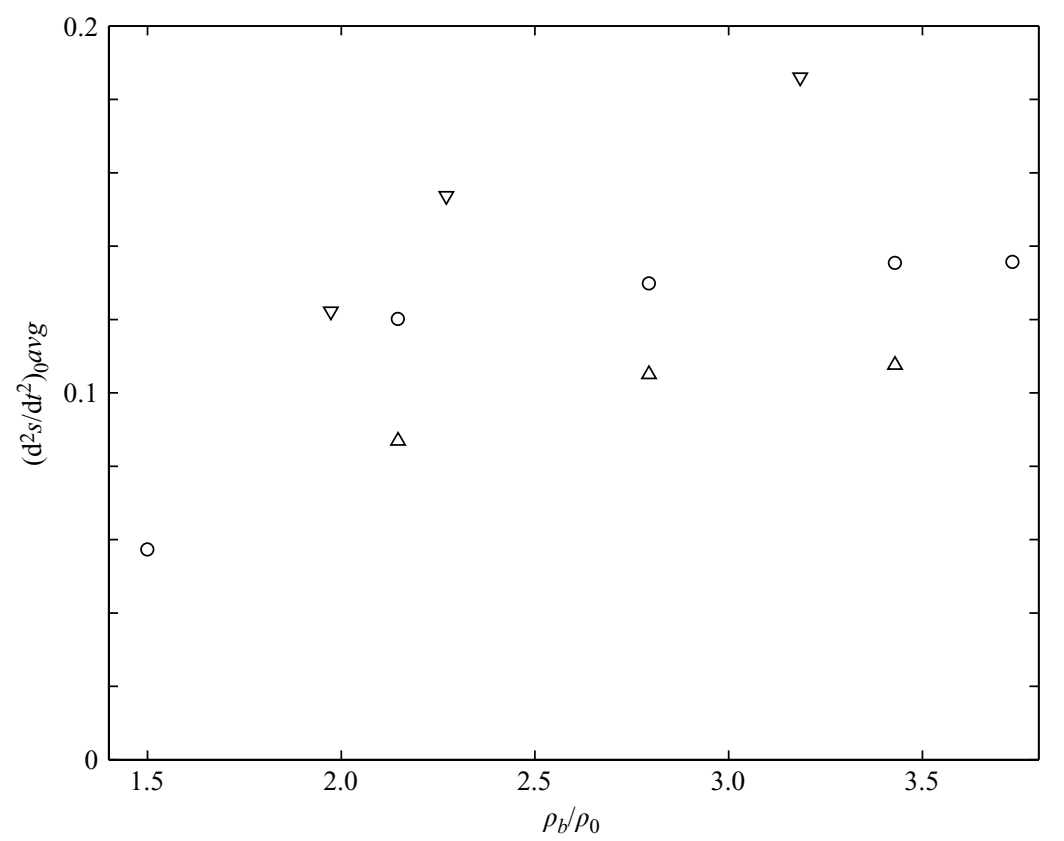

FIGURE 9. The normalized initial acceleration as a function of the specific gravity. $\bigcirc$, wedge series $\mathrm{A} ; \triangle$, wedge series $\mathrm{B} ; \nabla$, hemisphere.

is anticipated:

$$
R=f\left(\theta, \Delta, l, \rho_{b}, \rho_{o}, g, \mu, \beta, \Gamma\right),
$$

in which $f$ represents the functional relationship, $l$ a characteristic length of the body, $\rho_{b}$ the density of the body, $\rho_{o}$ the density of the fluid, $\mu$ the dynamic viscosity of the fluid, $\beta$ refers to the body shape, and $\Gamma$ is related to the Coulomb friction between the body wheels and the slope. The angle of the incline, the mass of the body, its displaced fluid mass, the body shape, and the Coulomb friction combined describe the kinematics of the body, i.e. the velocity time history, and thus, the initial body acceleration: $\left(\mathrm{d}^{2} s / \mathrm{d} t^{2}\right)_{o}$. As shown in the example in figure 5, the rundown appears to be formed before the body has moved one body length downslope and this corresponds to the rapid initial recession of the fluid behind the body (see figure 3). It is proposed that good descriptors of this effect are the parameters shown in (3.4), which can be replaced by the following functional expression assuming that the initial acceleration is the generator of the rundown and runup associated with the body motion:

$$
R=\phi\left(\Delta, l,\left(\mathrm{~d}^{2} s / \mathrm{d} t^{2}\right)_{o}, g\right)
$$

Defining the characteristic body length, $l$, as the length of the body in the $\xi$ direction, i.e. $b$, in non-dimensional form, (3.5) can be expressed functionally as:

$$
R / b=\psi\left(\Delta / b,\left(\mathrm{~d}^{2} s / \mathrm{d} t^{2}\right)_{o} / g\right) .
$$

With reference to (3.2), it can be seen that for a given slope, $\theta$, and Coulomb friction coefficient, $C_{n}$, the relative initial acceleration, $\left(\mathrm{d}^{2} s / \mathrm{d} t^{2}\right)_{o} / g$, is directly proportional to the specific gravity of the slide, $\gamma=\rho_{b} / \rho_{o}$. For the fully submerged slides, i.e. wedges of Series A and B and the hemisphere, the relation between the specific gravity and the relative initial acceleration is presented in figure 9. It is seen that for a given shape, 


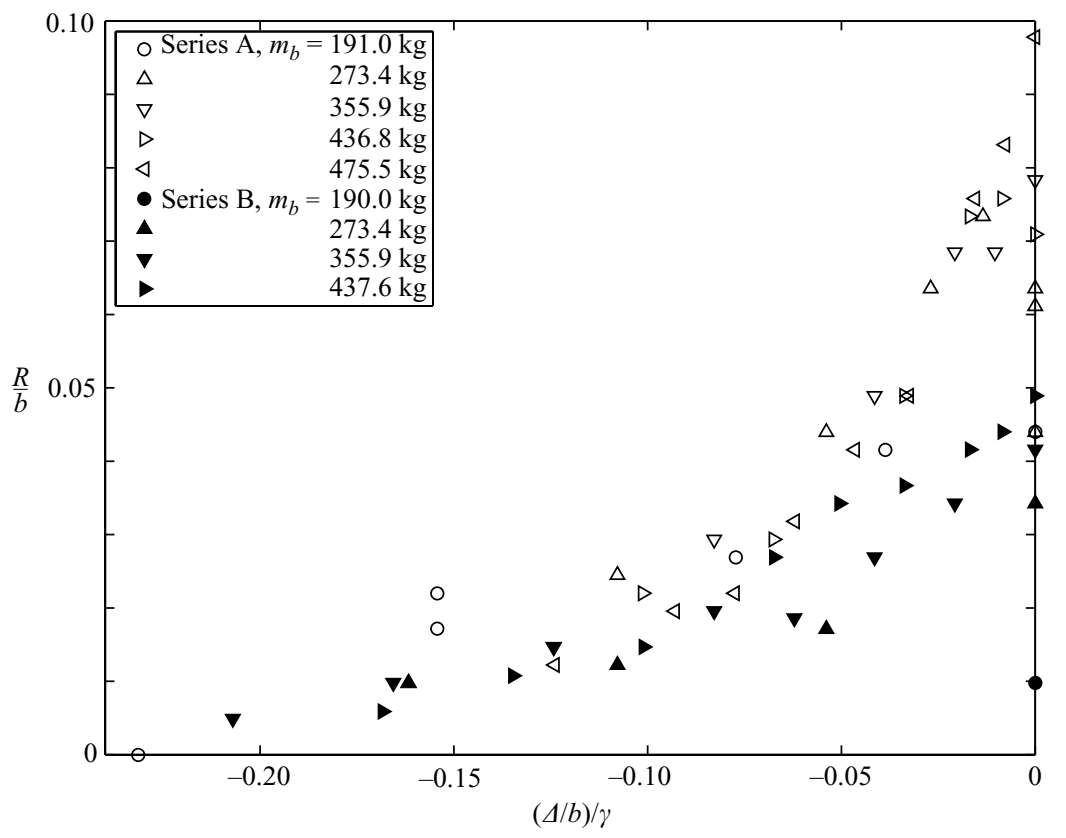

FIGURE 10. The normalized runup as a function of $(\Delta / b) / \gamma$ for the submerged wedge series.

the relative initial acceleration increases with increasing specific gravity. For a given specific gravity, the minimum initial acceleration corresponds to the wedge Series B and the maximum to the hemisphere. This implies that the wedge Series B is the least 'streamlined' of the three bodies as far as the initial acceleration is concerned. Considering the relation between the initial acceleration and the specific gravity, (3.6) can be simplified as:

$$
R / b=\Psi(\Delta / b, \gamma) .
$$

Considering first the case for the slide initially submerged, as the submergence increases, i.e. $\Delta / b<0$, the runup should decrease, and as the initial acceleration (or the specific gravity of the body) increases, the runup should increase. In figure 10, we plot the variation of the relative runup, $R / b$, for the wedges of Series A and $\mathrm{B}$ and for submerged initial conditions against $\zeta_{1}=(\Delta / b) / \gamma$, which is the simplest combination of the parameters appearing in (3.7). It appears that for both wedge series, the data reasonably collapse when plotted in this manner. The relative runup decreases from a maximum at $\zeta_{1}=0$ to approach zero asymptotically as $\zeta_{1}$ tends to $-\infty$. As seen in figure 10, for a given initial submergence as the specific gravity of the slide increases, the relative runup increases. The runup for the Series B wedge is consistently less than for the Series A units, which indicates that the slide shape might play an important role through the variation in the initial acceleration as shown in figure 9.

For the subaerial slides, i.e. $\Delta / b>0$, we show the variation of the runup vs. $\zeta_{2}=(\Delta / b) \gamma$ in figure 11 for the wedges Series A and B. For a given slide as the initial position, $\Delta / b$, increases, the runup increases and for a given initial position as the specific gravity increases, i.e. $\gamma$ increases, the runup increases. As for the submerged case, the runup corresponding to the Series B wedges is consistently less that for the Series A wedges. However, when fully emerged, the runup for both is about the same. We remark here that the data scattering appearing in figures 10 and 11, especially 


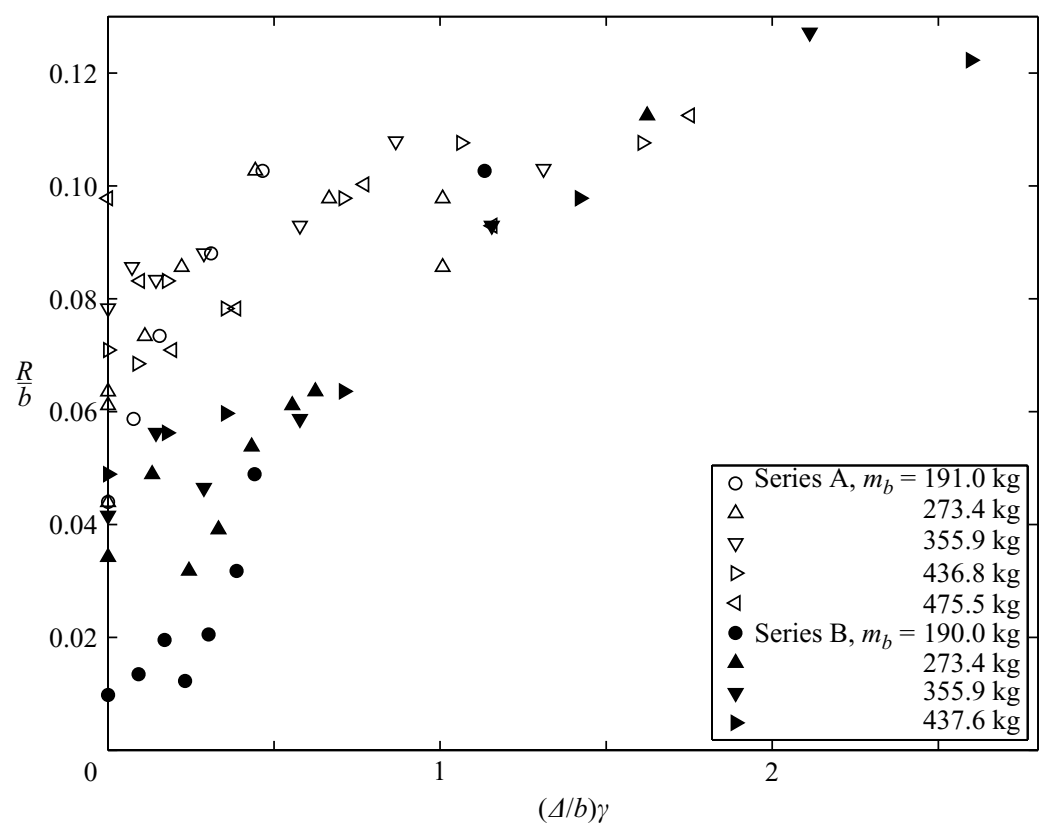

FIGURE 11. The normalized runup as a function of $(\Delta / b) \gamma$ for the subaerial wedge series.

near $\Delta / b \sim 0$, suggest that the runup might depend on the initial submergence and the specific weight separately. Finally, the effects of sidewall on the maximum runup could also become important in some cases. This will be discussed in a later section.

Indeed, for a given specific gravity, as $\Delta / b$ increases, the runup of the wedges corresponding to Series A and Series B approach each other and reach a maximum for a fully emerged body of about 0.12 .

The runup for the submerged and the subaerial hemispheres as a function of $\zeta_{1}$ or $\zeta_{2}$ are presented in figures 12 and 13, respectively. In these cases, the swash on the slope was measured using resistance wave gauges embedded in the slope. Therefore, both the runup and the rundown were obtained. In figure 12, for submerged conditions, the runup is somewhat smaller than the rundown for the same submergence and specific gravity. However, for an initial subaerial location of the hemisphere, the rundown is of the order of twice the runup. For the fully emerged case, the runup for the hemisphere is approximately the same as that for the wedges $(R / b \approx 0.13)$, whereas the rundown is about twice that $(R / b \approx 0.25)$.

It is interesting to extend the discussion of the variation of the relative runup with $\zeta$ for other solid submerged sliding bodies $(\Delta / b \leqslant 0)$. Since the initial acceleration is relatively constant for the submerged regime, the decrease in the relative runup with $\zeta$ must be due to the increasing initial submergence, $\Delta / b$. Referring to figure 8 , for the same body, if the slope angle, $\theta$, is decreased, the initial acceleration will decrease accordingly, since $\alpha$, i.e. $F_{\text {Coulomb }} /\left(m_{b} g\right)$, increases as $\theta$ decreases. If we assume that the relative runup behaves in a manner similar to that shown in figure 12 for any body shape, in the submerged region $(\Delta / b \leqslant 0)$, it would be expected that for the same $\zeta$ as the slope decreases $R / b$ would decrease. This implies that for the same runup magnitude, $R$, as the slope decreases, the size of the body, $b$, must increase accordingly. Hence, for a given initial acceleration, on small slopes only underwater landslides with very large dimensions would be potentially dangerous. If we postulate 


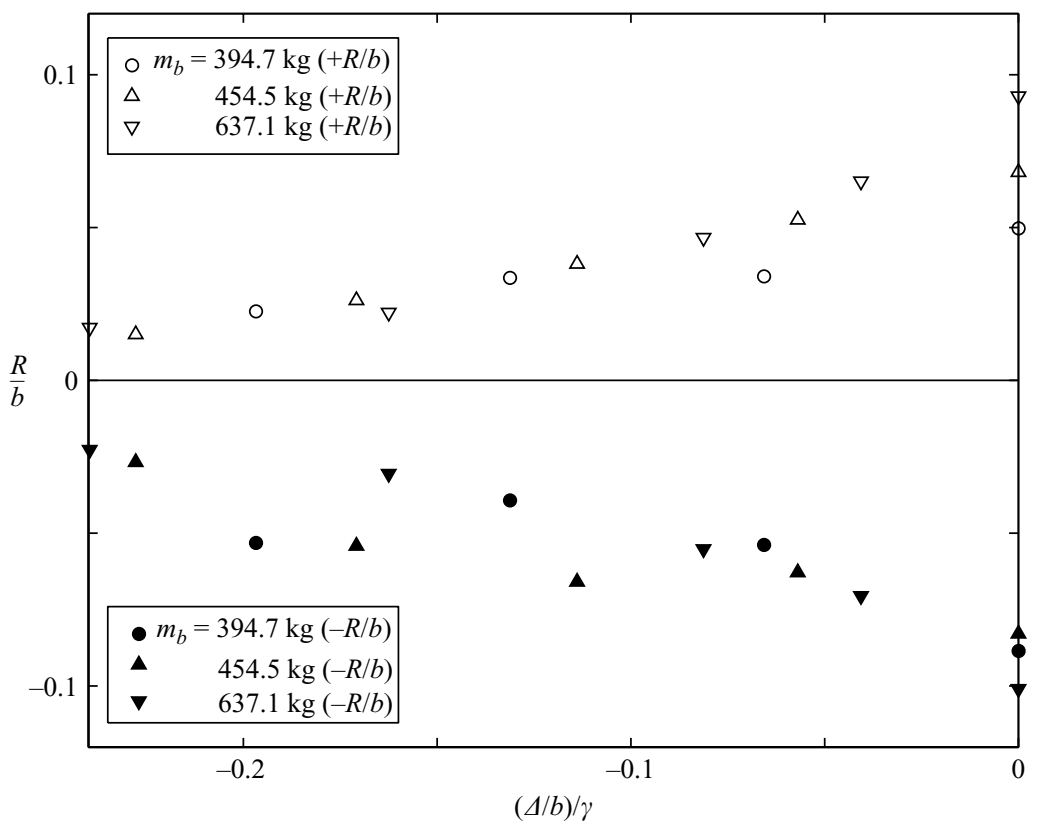

FIGURE 12. The normalized runup and rundown as functions of $(\Delta / b) / \gamma$ for the submerged hemisphere series.

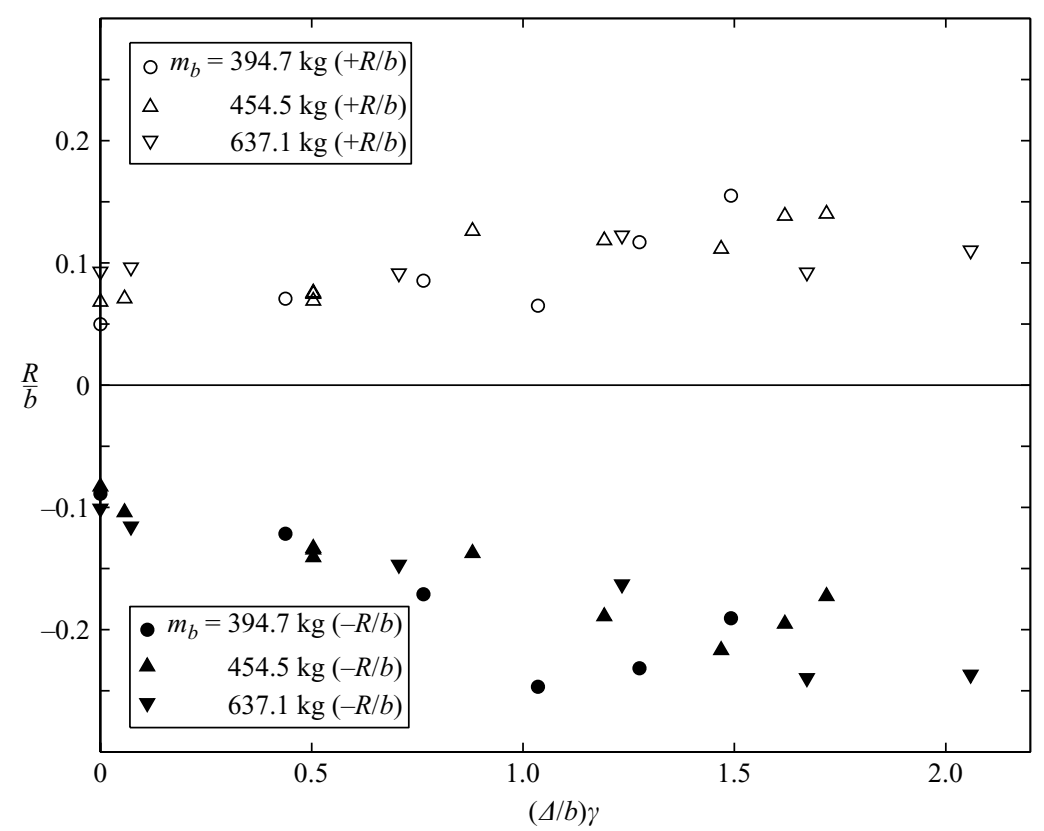

FIGURE 13. The normalized runup and rundown as functions of $(\Delta / b) \gamma$ for the subaerial hemisphere series.

that submarine material landslides behave in a manner similar to solid-body slides, the runup and the rundown would be controlled by size, submergence and initial motion time history. 

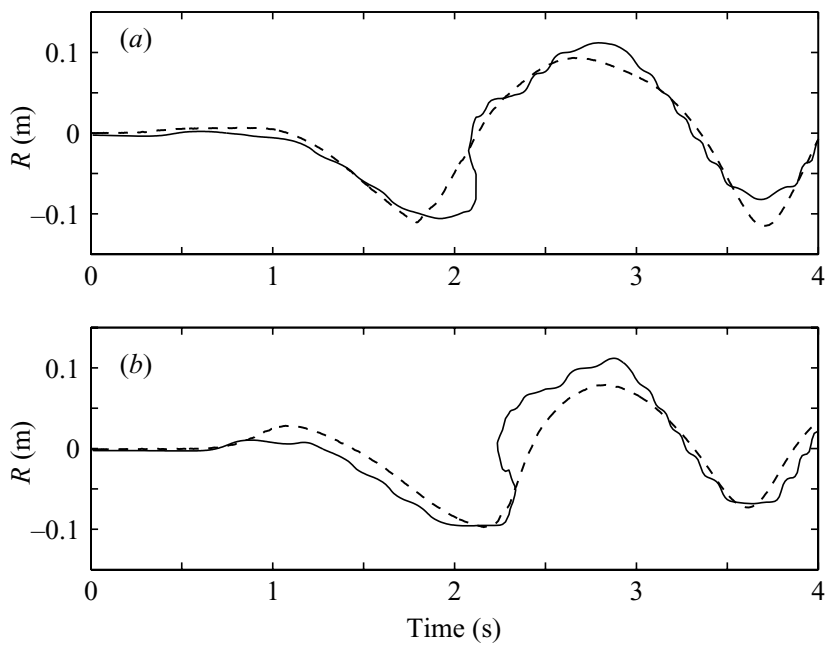

Figure 14. The comparison between numerical results (solid lines) and experimental data (broken lines) for the time histories of runup height at (a) gauges 2 and 3. (b) $\Delta=0.454 \mathrm{~m}$, $\gamma=3.24$.
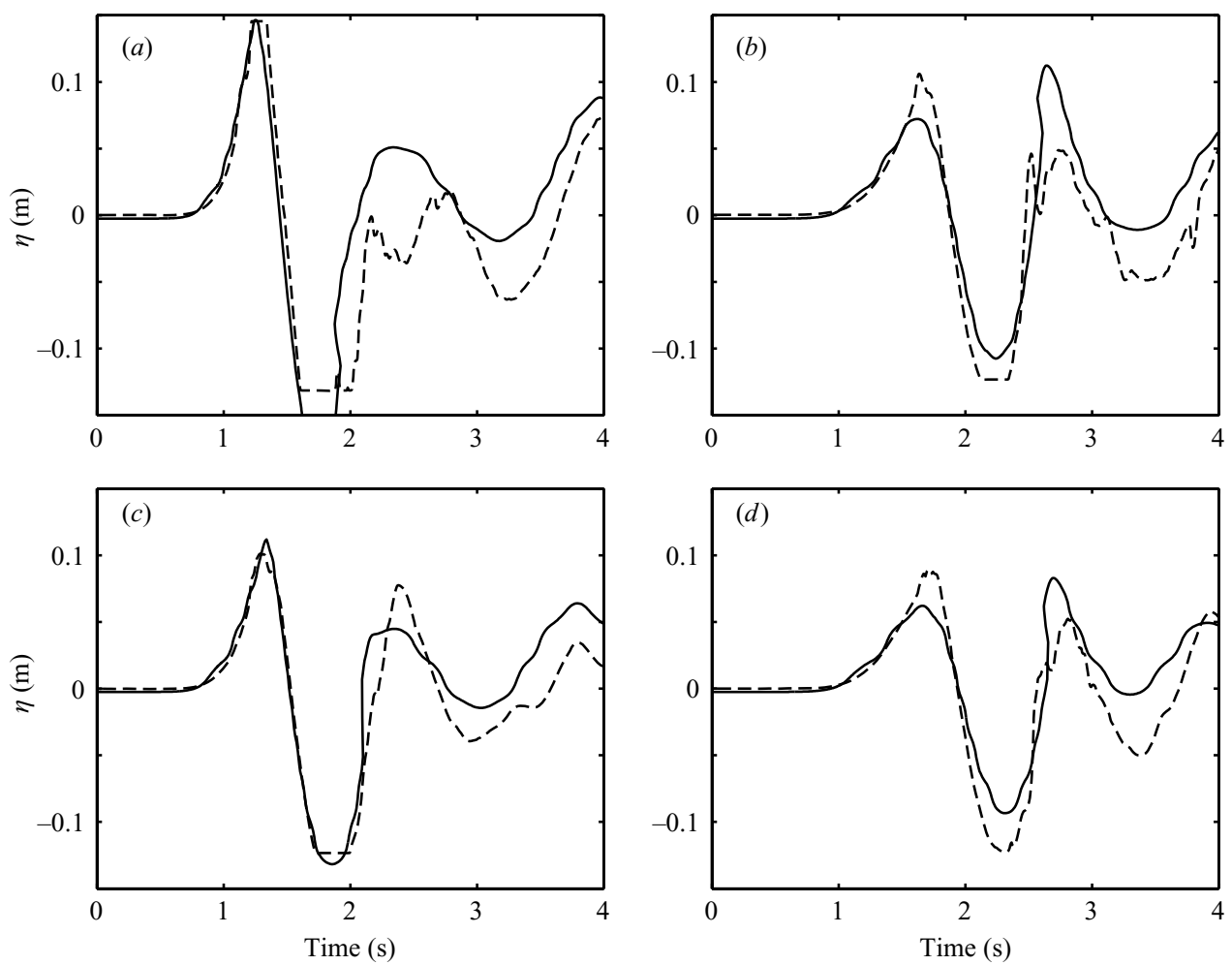

FIGURE 15. The comparison between numerical results (solid lines) and experimental data (broken lines) for the time histories of free-surface fluctuations at wave gauges $(a) 4,(b) 5$, (c) $6,(d) 7 ; \Delta=0.454 \mathrm{~m}, \gamma=3.24$. The coordinates of the wave gauges are: gauge $4(x=1.83 \mathrm{~m}$, $y=0.00 \mathrm{~m})$; gauge $5(2.74 \mathrm{~m}, 0.00 \mathrm{~m})$; gauge $6(1.83 \mathrm{~m}, 0.635 \mathrm{~m})$; gauge $7(2.74 \mathrm{~m}, 0.635 \mathrm{~m})$. 

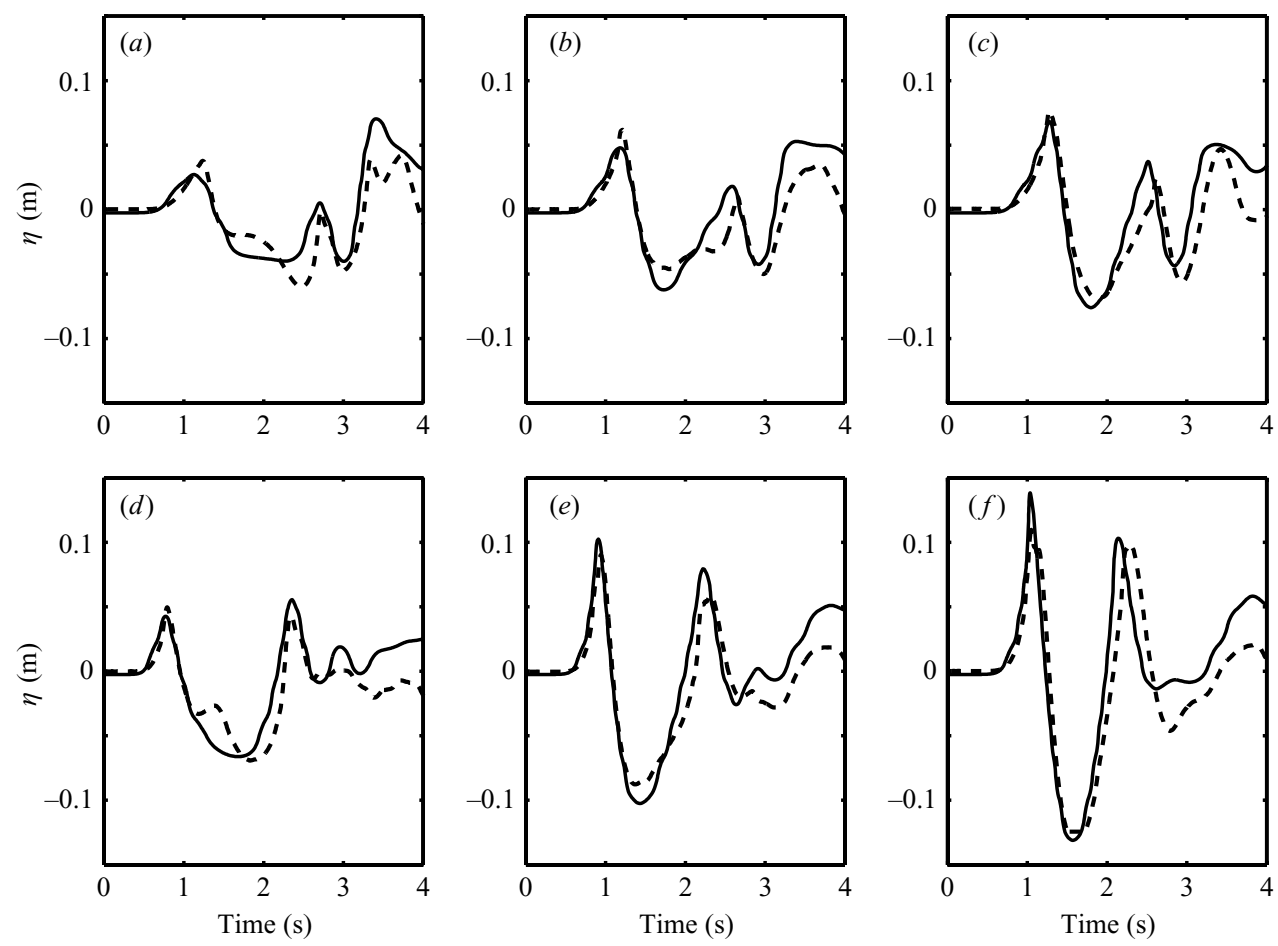

FIGURE 16. The comparison between numerical results (solid lines) and experimental data (broken lines) for the time histories of free-surface fluctuations at wave gauges 8-13; $\Delta=0.454 \mathrm{~m}, \gamma=3.43$. The coordinates of the wave gauges are: $(a)$ gauge $8(x=0.4826 \mathrm{~m}$, $y=1.092 \mathrm{~m}) ;(b)$ gauge $9(0.8636 \mathrm{~m}, 1.092 \mathrm{~m}) ;(c)$ gauge $10(1.2446 \mathrm{~m}, 1.092 \mathrm{~m}) ;(d)$ gauge 11 $(0.4826 \mathrm{~m}, 0.635 \mathrm{~m}) ;(e)$ gauge $12(0.8636 \mathrm{~m}, 0.635 \mathrm{~m}) ;(f)$ gauge $13(1.2446,0.635)$.

\section{Numerical results and comparisons with experimental data}

Numerical simulations have been performed for all 46 wedge Series A experiments with different initial elevations and specific weights. We give the comparison between numerical solutions and laboratory data for just one subaerial case; other cases can be found in $\mathrm{Wu}$ (2004). Detailed discussions for the complex three-dimensional flow based on the numerical results are also given.

\subsection{A subaerial slide simulation}

In this section, simulation results for a subaerial wedge slide will be compared with the experimental data in order to check the accuracy of the numerical model.

The initial elevation of the wedge is $0.454 \mathrm{~m}$ above the SWL $(\Delta=0.454 \mathrm{~m})$. The specific weight $\gamma=3.43$. The computational domain is $6.6 \mathrm{~m}$ in the offshore $(x)$ direction, $3.7 \mathrm{~m}$ in the spanwise $(y)$ direction, and $3.3 \mathrm{~m}$ in the vertical $(z)$ direction. Convergence tests based on various grid sizes were performed. The numerical results reported in this section have total grid number $60 \times 50 \times 60$ and are grid independent. Non-uniform grids are used in the $x$ and $z$ directions with the finest grid sizes, $\Delta x=0.0391 \mathrm{~m}$ and $\Delta z=0.0196 \mathrm{~m}$ located at the corner near the initial shoreline. A uniform grid, $\Delta y=0.074 \mathrm{~m}$, is adopted in the spanwise direction. The grid has been specially designed such that $\Delta x=2 \Delta z$. The beach is located diagonally across the $(x, z)$-plane. Therefore, along the beach and without considering the moving wedge, the effective cell volume is always equal to $50 \%$ of the local cell volume. This special design identifies the shoreline location without interfering with the irregular effective cell volume. 

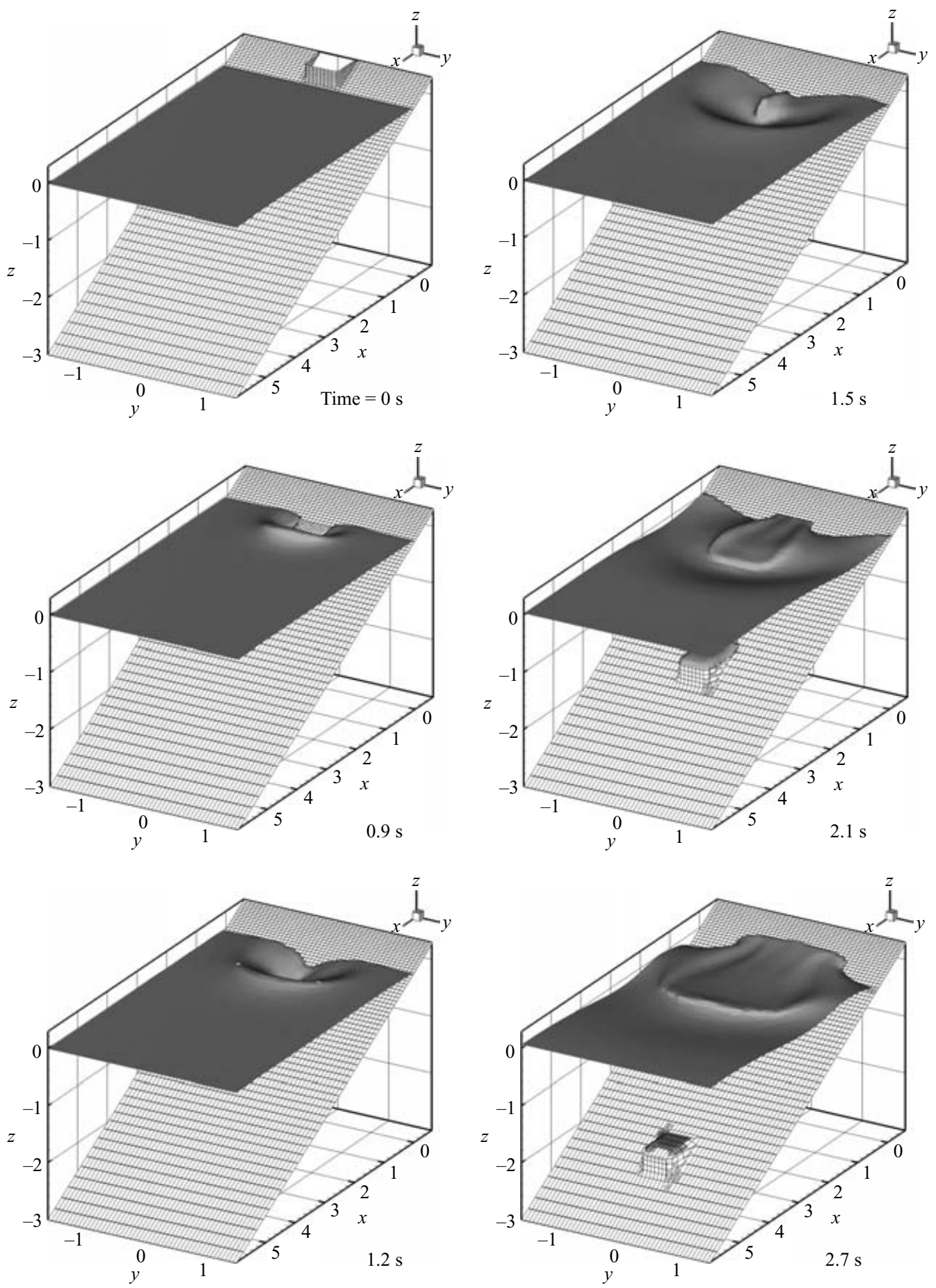

FIGURE 17. Snapshots of the free-surface profile for the sliding wedge with $\Delta=0.454 \mathrm{~m}$, and $\gamma=3.24$. The unit is the metre.

As discussed in the previous section, in the laboratory experiments, runup gauges were installed on the slope to provide runup time histories. The first runup gauge (gauge 2) is located along the edge of the wedge, $y=0.305 \mathrm{~m}$, the other one (gauge 3 ) 


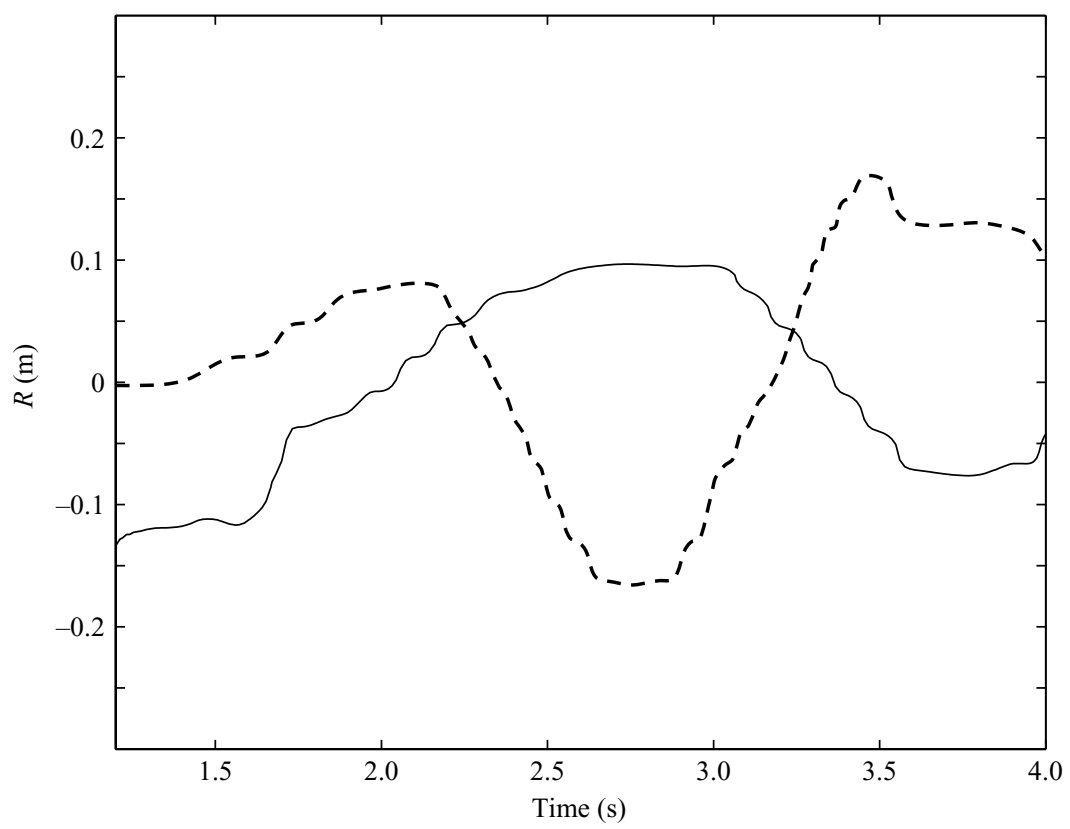

FIGURE 18. Time histories of the runup at - , the centreline and ---, the sidewall.

is located one wedge-width away from the centreline, $y=0.61 \mathrm{~m}$. Figure 14 shows the comparisons between numerical results and laboratory data for the time histories of shoreline movements. The solid lines are the numerical results and the broken lines are the experimental measurements. The numerical runup height is determined by the contour line where the water occupies $50 \%$ of the effective cell volume. A very good agreement is shown at gauge 2 . At gauge 3, numerical solutions slightly overpredict the maximum runup height and the disagreement is about $10 \%$. Overall, the numerical simulation captures the maximum runup height and its arrival time.

In the laboratory experiments, four wave gauges were installed in the seaward side of the slide and were labelled as gauges $4-7$. Their coordinates are given in figure 15, where comparisons of numerical results and experimental data for the free-surface fluctuations are presented. The solid lines are the numerical solutions and the broken lines are the numerical measurements. Gauges 4 and 6 are those closer to the shoreline. The comparison shows that the numerical simulation successfully predicts the leading-wave height as well as the phase speed. Gauges 5 and 7 show that the numerical solutions slightly underpredict the leading wave height. However, the numerical model is able to predict the phase of the waves. Wave gauges 8-13 were installed on one side of the slide to record the lateral propagation of slide generated waves. Both numerical results and laboratory data are shown in figure 16, very good overall agreement is observed.

Based on the numerical results, we will now present a sequence of snapshots of the surface elevation, velocities and shoreline movements, which are not measured in the experiments, to illustrate the complex flow characteristics.

Figure 17 shows the snapshots of the overall free-surface profiles as the wedge moves down the incline. The SWL shoreline is at the intersection of $x=0$ and $z=0$. As the wedge enters the water body, it pushes the water in front of it and generates the leading positive seaward-going wave (time $=0-0.9 \mathrm{~s}$ ). The leading wave 

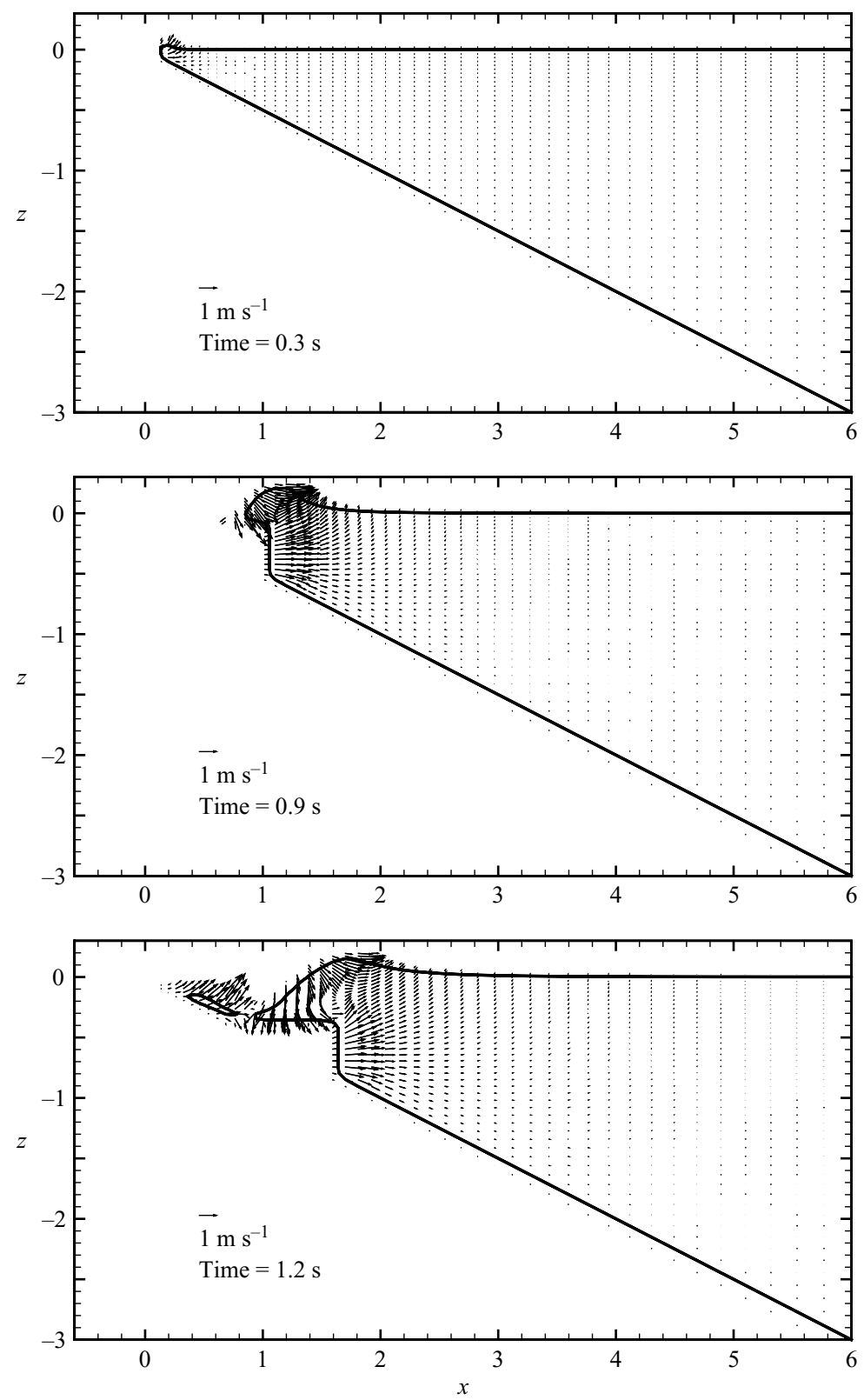

FIGURE 19. For caption see facing page.

propagates in the radial direction and reaches the sidewall at about time $=1.5 \mathrm{~s}$. When the wedge is totally submerged, the water surface above the wedge is initially depressed owing to the low pressure in the wake zone and large free-surface gradients are created in the alongshore direction. Consequently, strong lateral flows converge towards the centreline (time $=0.9-1.2 \mathrm{~s}$ ). As observed in the experiments (see figure 3), the convergent free-surface flows collide and rebound along the centreline, generating a large positive wave radiating away from the source region $($ time $=1.2-2.7 \mathrm{~s})$. The rebounding wave is the key contributor to the maximum runup and to the largest 

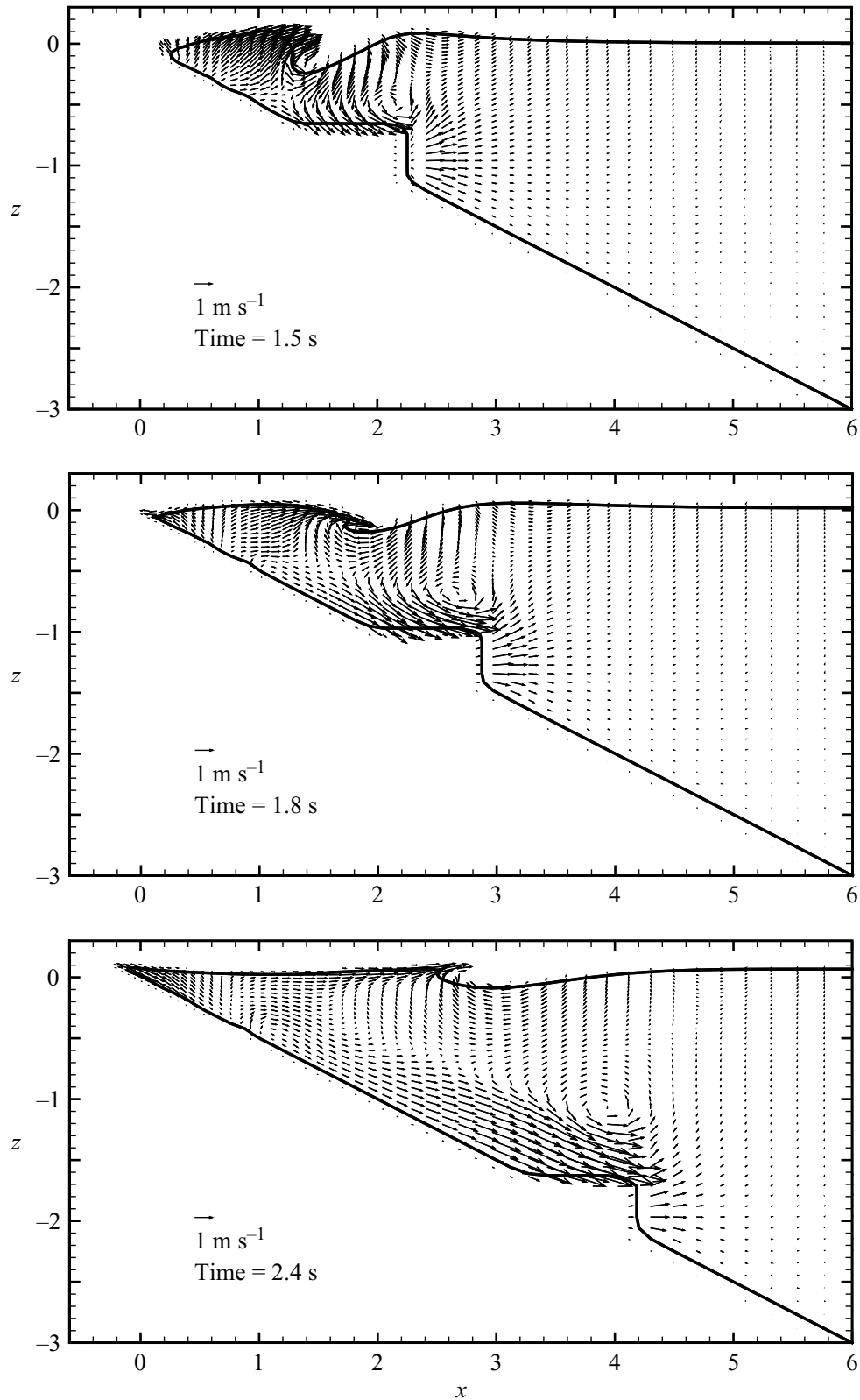

FIGURE 19. Snapshots of velocity vectors on the centreline vertical plane for the sliding wedge with $\Delta=0.454 \mathrm{~m}$, and $\gamma=3.24$. The unit is the metre.

leading wave towards the off-shore direction. The shoreline at time $=2.1 \mathrm{~s}$, shown in figure 17, has highest runups at the sidewall. Subsequently, the shoreline oscillates like a standing wave as indicated in figure 18, which has significant impact on the maximum runup in the present case. For this particular experiment, after about $1.5 \mathrm{~s}$, solutions are gradually contaminated by the waves reflected from the sidewalls. The effects of sidewalls on the maximum runup will be discussed in a later section. 

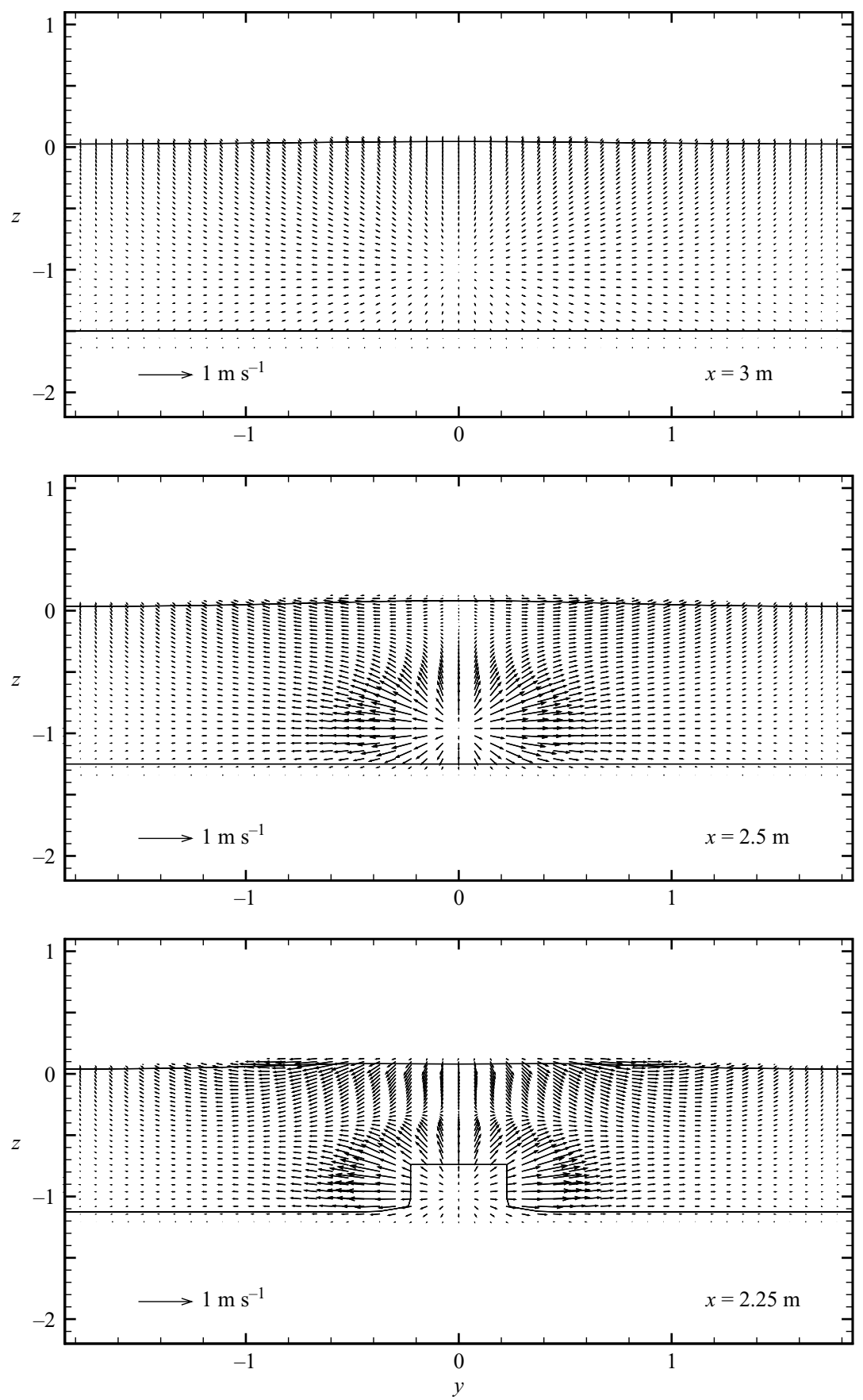

FIGURE 20. For caption see facing page.

Since it is difficult to measure experimentally and present the transient threedimensional flow velocity field, we will present here snapshots of numerical results for velocity vectors on various vertical and horizontal planes. First, a sequence of velocity plots on the vertical plane along the centreline $(y=0)$ is shown in figure 19 . As anticipated, from time $0-0.9 \mathrm{~s}$, strong seaward velocities are generated by the 

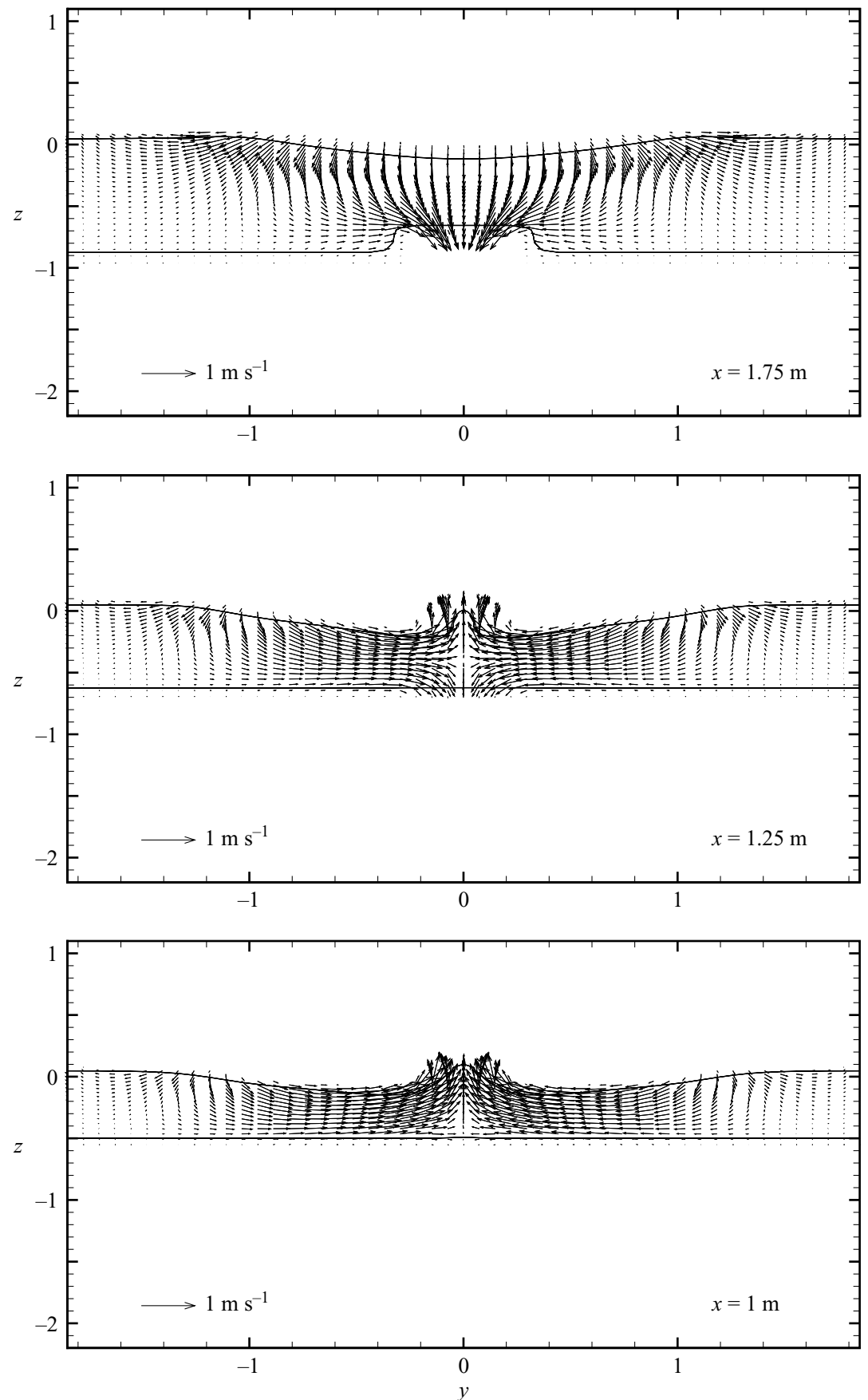

FIGURE 20. Snapshots of velocity vectors on the vertical $(y, z)$-planes at time $1.5 \mathrm{~s}$ for the sliding wedge with $\Delta=0.454 \mathrm{~m}$, and $\gamma=3.24$. The unit is the metre.

sliding wedge. After time $0.9 \mathrm{~s}$, the wedge is submerged and induces large downward velocities above the wedge. While the free surface is initially depressed above the wedge because of its continuing downward movement, a seaward propagating overturning wave is formed owing to the convergence of the lateral flows (see time $1.5 \mathrm{~s}$ and 

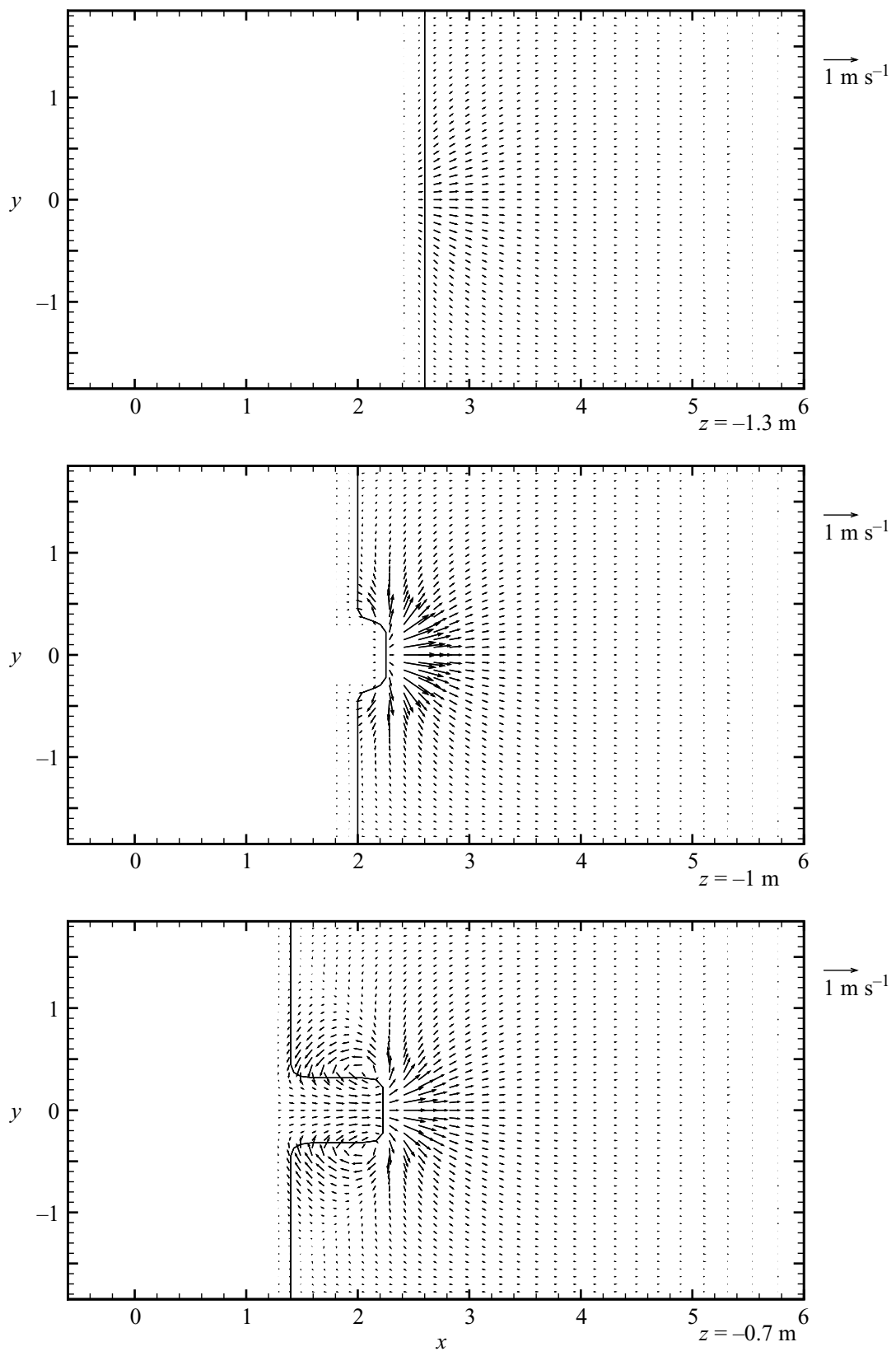

FIGURE 21. For caption see facing page.

$1.8 \mathrm{~s})$. Wave breaking and energy dissipation play important roles during this wavegeneration process. The complex velocity field is strongly three-dimensional, indicating that using depth-integrated equation models to estimate the initial slide-generated waveform might have significant errors. From time 2.1-2.7 s, the velocity distribution shows that a strong seaward flow has been generated by the wedge motion, and has a thickness about 1.5-2.0 times the front face height of the wedge. Above this seaward current, a returning onshore current appears and there also exists an eddy between 

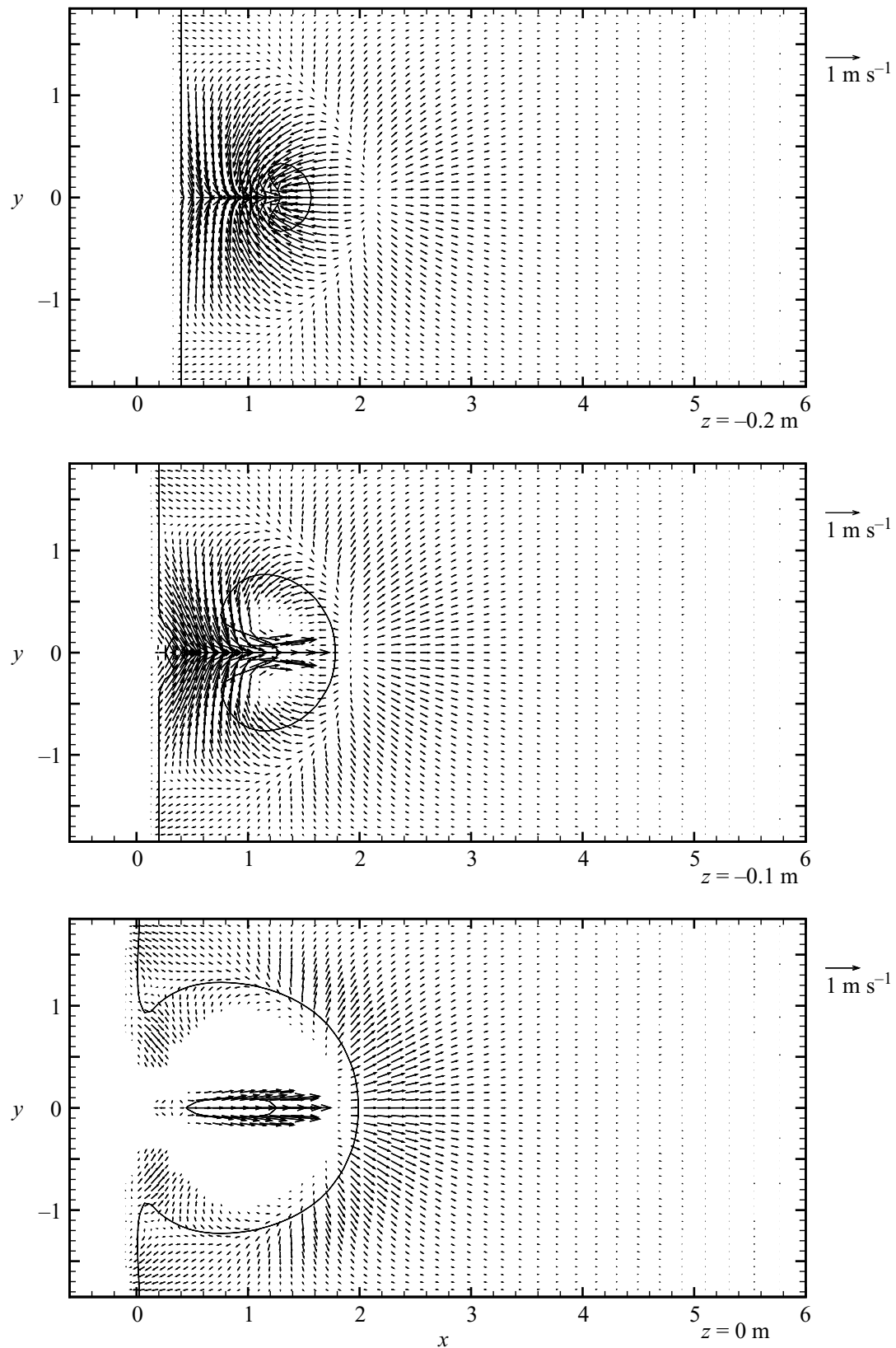

FIGURE 21. Snapshots of velocity vectors on the horizontal $(x, y)$-planes at time $1.5 \mathrm{~s}$ for the sliding wedge with $\Delta=0.454 \mathrm{~m}$, and $\gamma=3.24$. The unit is the metre.

two opposing currents (see time $2.4 \mathrm{~s}$ ). The seaward propagating wave encounters the onshore current, and the wave breaking persists with a reducing energy propagation speed. During this period, the rebounding wave also pushes water landwards near the shoreline, creating the maximum runup. We remark here that although the magnitude of the seaward velocity in the vicinity of the sliding wedge is quite large, it is confined within a narrow region. As the wedge moves into deeper water, the influence of the moving wedge on the wave generation diminishes. 

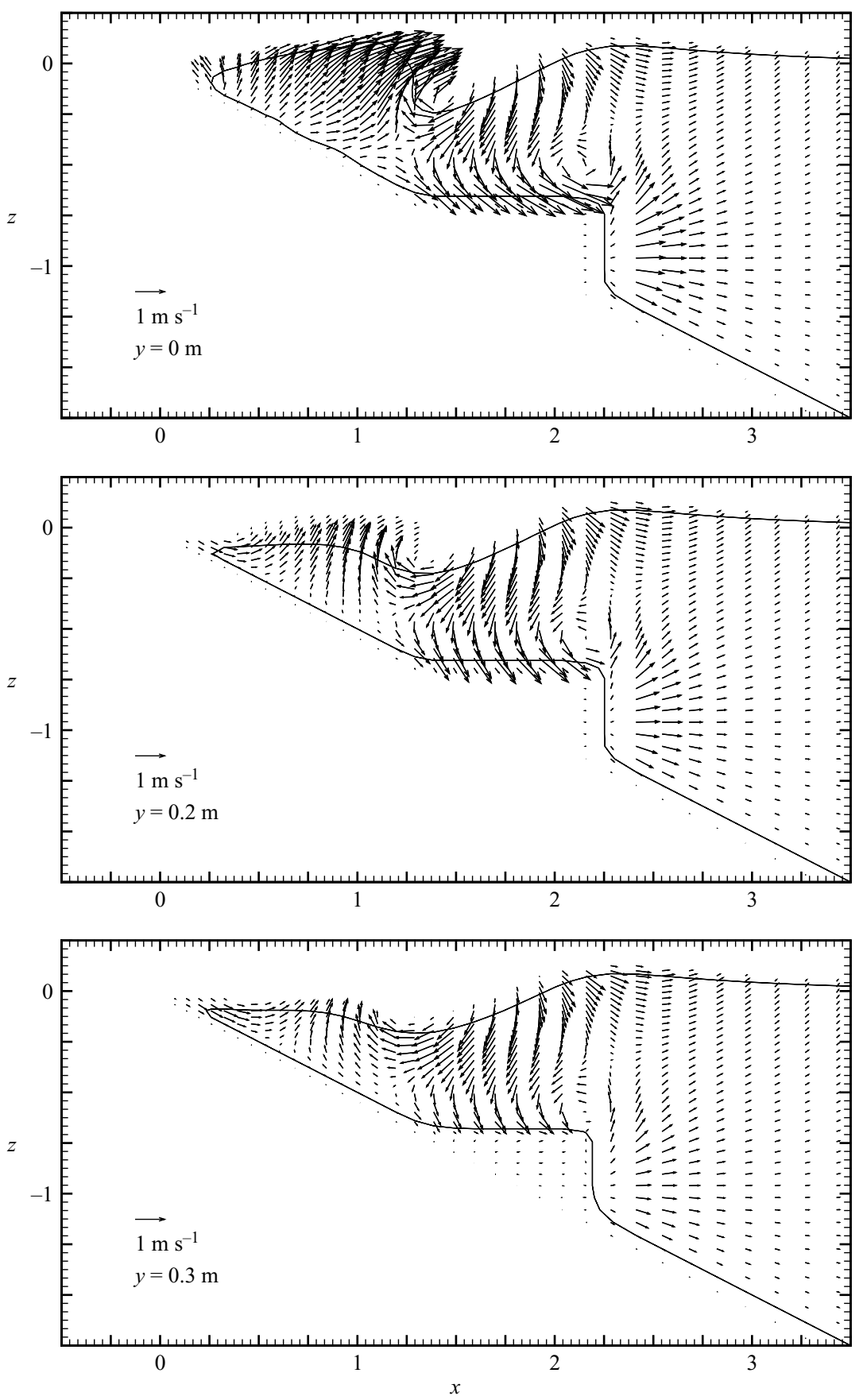

FIGURE 22. For caption see facing page.

To illuminate the complex three-dimensional flow pattern, we will provide additional velocity distributions on several vertical and horizontal planes at time $1.5 \mathrm{~s}$. At this moment (time $1.5 \mathrm{~s}$ ), the wedge is fully submerged and generates a complex flow pattern. We first show the velocity distributions on the $(y, z)$-planes from $x=3.0 \mathrm{~m}$ to $x=0.25 \mathrm{~m}$, where the SWL shoreline is located ( $x=0$ and $z=0$ in figure 20). On 

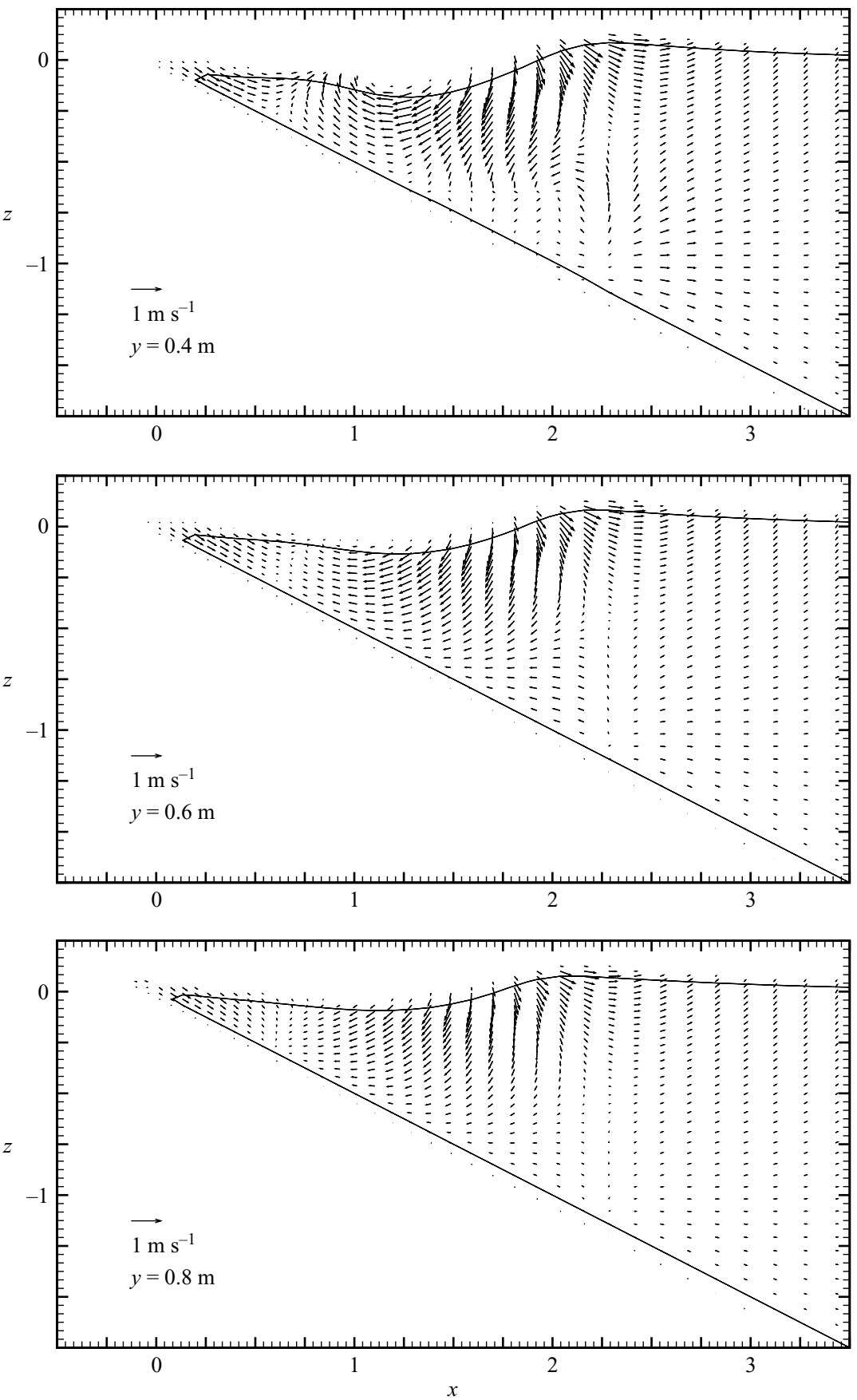

FIGURE 22. Snapshots of velocity vectors on the vertical $(x, z)$-planes at time $1.5 \mathrm{~s}$ for the sliding wedge with $\Delta=0.454 \mathrm{~m}$, and $\gamma=3.24$. The unit is the metre.

each plot, the fluid velocity vectors are shown and the dotted lines are either the free surface or the interface between water and solid surface (beach or wedge). We should point out that because of the interpolation scheme used in the plotting software, the corners of the wedge in some of these plots have been rounded off. At time 

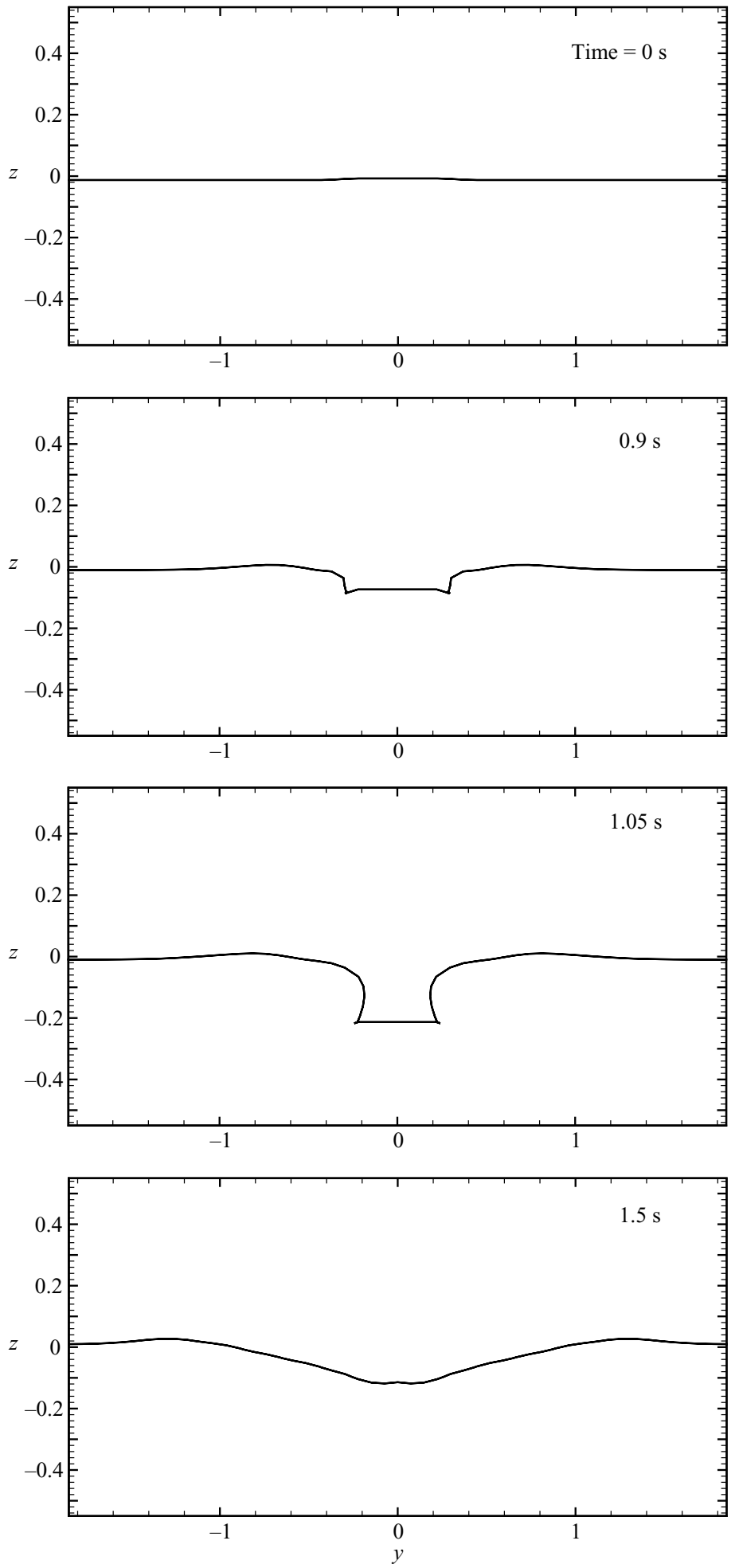

FIGURE 23. For caption see facing page. 

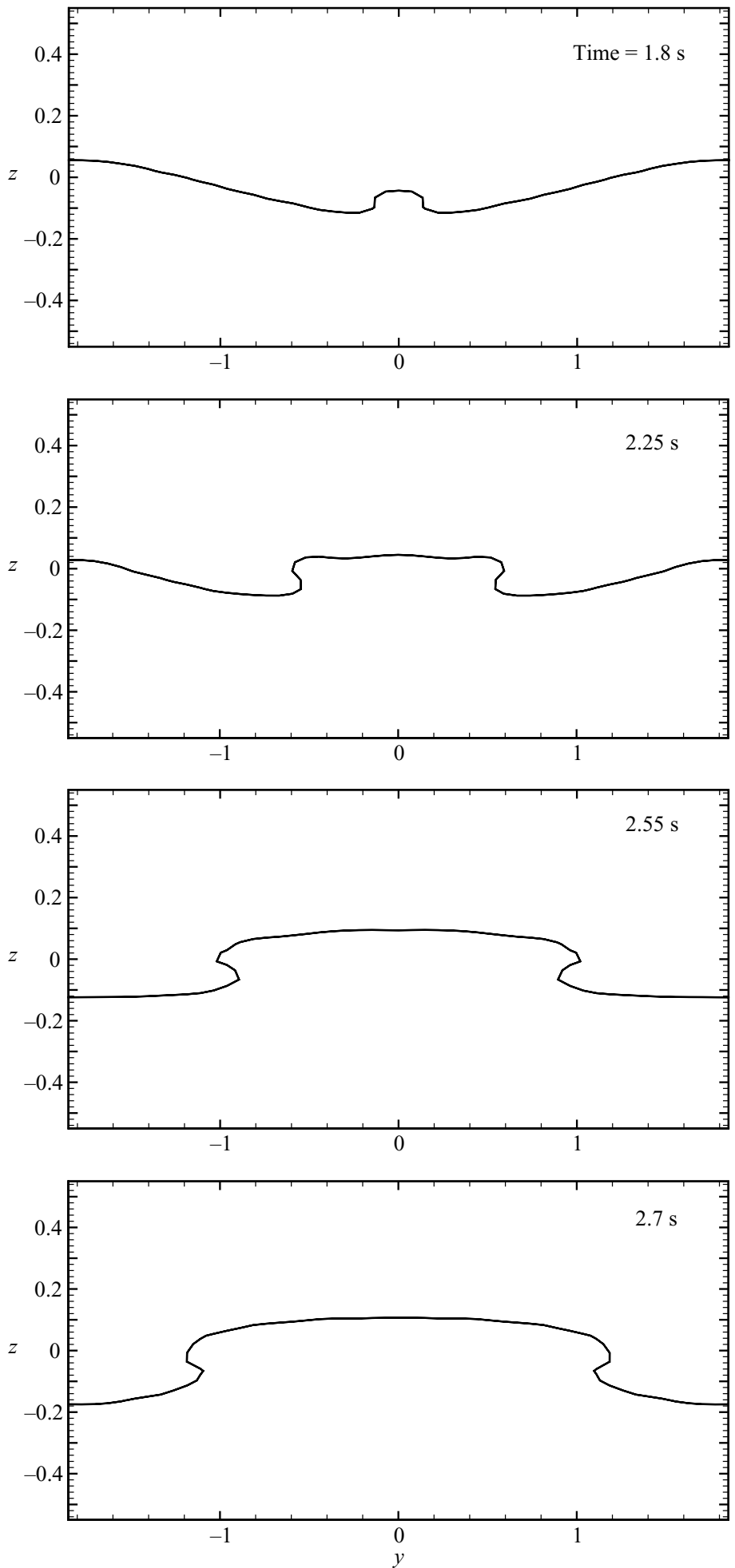

FIGURE 23. Snapshots of shoreline movements for the sliding wedge with $\Delta=0.454 \mathrm{~m}$, and $\gamma=3.24$. The unit is the metre. 
$1.5 \mathrm{~s}$, the cross-sections from $x=3.0 \mathrm{~m}$ to $x=2.5 \mathrm{~m}$ are in front of the wedge. It is clear that water is pushed away from the centreline. The region mostly affected by the moving wedge has a length scale about 3 times the width of the wedge laterally and twice the height of the wedge vertically. The free surface is not significantly influenced by the wedge movement. From $x=2.25 \mathrm{~m}$ to $x=1.75 \mathrm{~m}$, the cross-sections intersect with the wedge. The dominating feature on these cross-section is the strong downward flow accompanied by the depressed free surface. Near the front of the wedge $(x=2.25 \mathrm{~m})$ water is still being pushed away from the wedge. However, starting from $x=1.75 \mathrm{~m}$, convergent lateral currents at both sides of the wedge start to appear. These convergent currents become very significant and dominate the flow patterns in the lee side of the wedge for $x>1.25 \mathrm{~m}$. These convergent currents collide with each other and generate strong rebounding waves.

Figure 21 shows snapshots of velocity distributions at time $1.5 \mathrm{~s}$ on several horizontal planes from $z=-1.3 \mathrm{~m}$ to $z=0 \mathrm{~m}$. The solid lines on these plots denote the intersecting lines between the horizontal plane with the beach, the wedge and the free surface. From $z=-1.3 \mathrm{~m}$ to $z=-1.0 \mathrm{~m}$, the flows in the vicinity of the wedge are in the radial direction with the largest velocity in front of the wedge. On the horizontal planes with higher elevations, $z=-0.7 \mathrm{~m}$, the presence of the wedge is felt more strongly and two vertical eddies appear on the side of the wedge. Roughly speaking, the wedge is totally submerged below $z=-0.7 \mathrm{~m}$. Above that elevation, the horizontal velocity patterns change drastically from one horizontal plane to another, suggesting a strong three-dimensional flow structure. On the cross-sections from $z=-0.2 \mathrm{~m}$ and $z=0 \mathrm{~m}$, a portion of the horizontal planes are exposed to the air, i.e. a portion of the free surface is underneath these horizontal planes. It is also clear that a second seaward propagating wave is generated owing to the collision of convergent flows.

Figure 22 displays snapshots of velocity distributions at time $1.5 \mathrm{~s}$ on several vertical planes (( $x, z)$-planes) from $y=0 \mathrm{~m}$ to $y=0.8 \mathrm{~m}$, where $y=0 \mathrm{~m}$ is the centreline of the tank and $y=1.85 \mathrm{~m}$ denotes the sidewall. Note that the width of the wedge is $0.61 \mathrm{~m}$, the edges at $y=\mp 0.305 \mathrm{~m}$. It is clear that strong wave breaking occurs near the centreline of the tank. A pair of vortices appear above the moving wedge. At this instant, the rebounding wave just starts to form, the shoreline is moving in the landward direction only in the neighbourhood of the centreline. Away from the centreline, the shoreline is still withdrawing. At $y=0.6 \mathrm{~m}$ and $0.8 \mathrm{~m}$, the return (onshore) currents can also be observed.

The snapshots of the shoreline movement are shown in figure 23. Initially, the shoreline is dragged down by the sliding wedge. Around time $1.5 \mathrm{~s}$, the shoreline starts to move in the landward direction near the centreline and spreads out laterally. The lateral spreading is relatively uniform creating a top-hat shaped shoreline configuration. The maximum runup height is reached at time $2.7 \mathrm{~s}$ and is located at the centreline. The standing-wave type shoreline oscillations from time $1.8 \mathrm{~s}$ to time $2.7 \mathrm{~s}$ are clearly seen, which affects the value of the maximum runup.

\subsection{Maximum runup and sidewall effects}

As mentioned before, we have conducted 46 numerical simulations for the wedge Series A with different initial elevations and specific weights. In figure 24, numerical solutions for the normalized maximum runup are plotted together with the laboratory data on the numerical model, both laboratory data and numerical solutions for the subaerial cases and in figure 25 for the submerged cases. Overall, the maximum runup heights predicted by the numerical model agree well with the laboratory data in the region where $(\Delta / b) \gamma>0.6$ and $(\Delta / b) / \gamma<-0.06$. However, the numerical model 


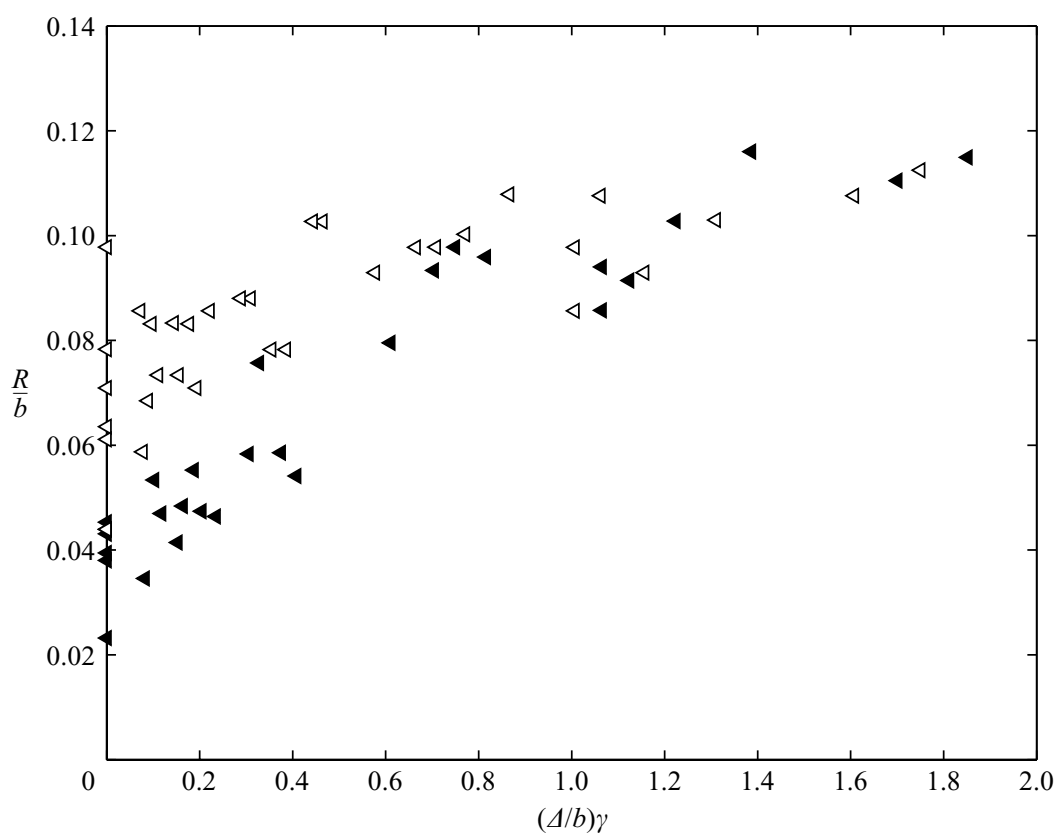

FIGURE 24. The normalized maximum runups obtained from both $\triangleleft$, experiments and 4 , numerical simulations are plotted against $(\Delta / b) \gamma$ for subaerial slides.

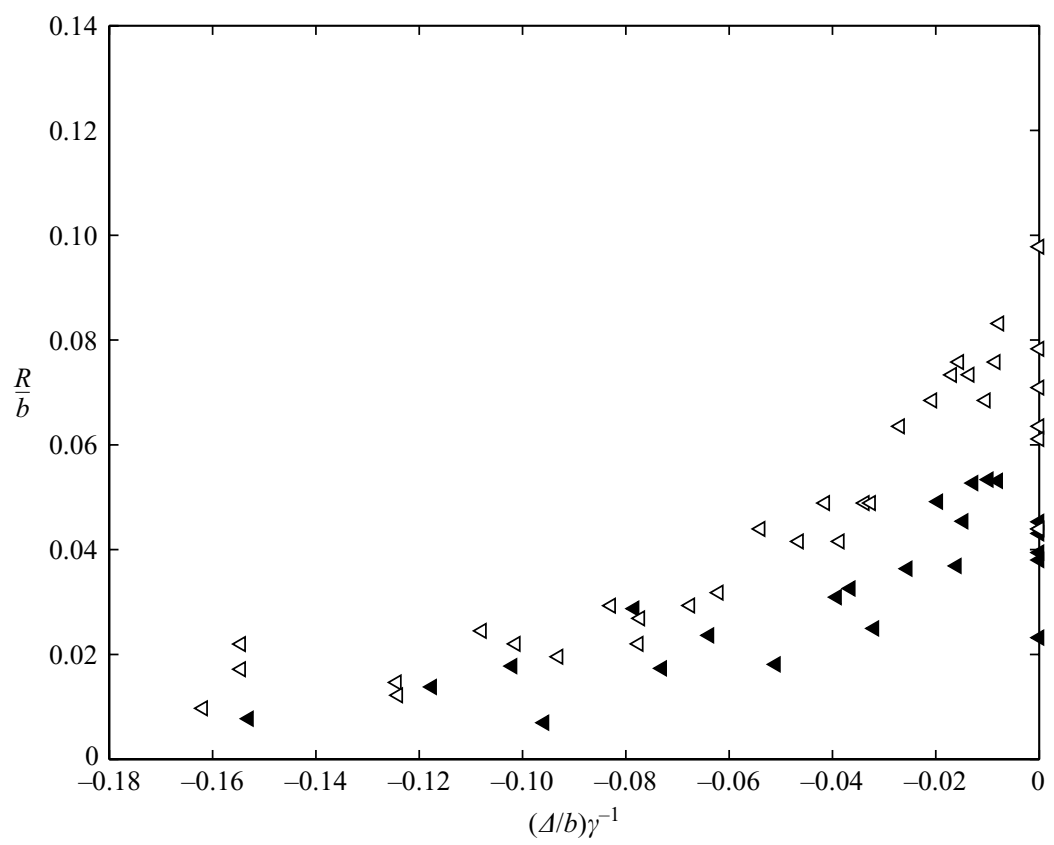

FIGURE 25. The normalized maximum runups obtained from both $\triangleleft$, experiments and numerical simulations are plotted against $(\Delta / b) \gamma^{-1}$ for submerged slides.

underpredicts the maximum runup height at the region where $\Delta$ is close to zero, where the scattering of experimental data are also quite large. The precise reason for the discrepancies is still not clear. 

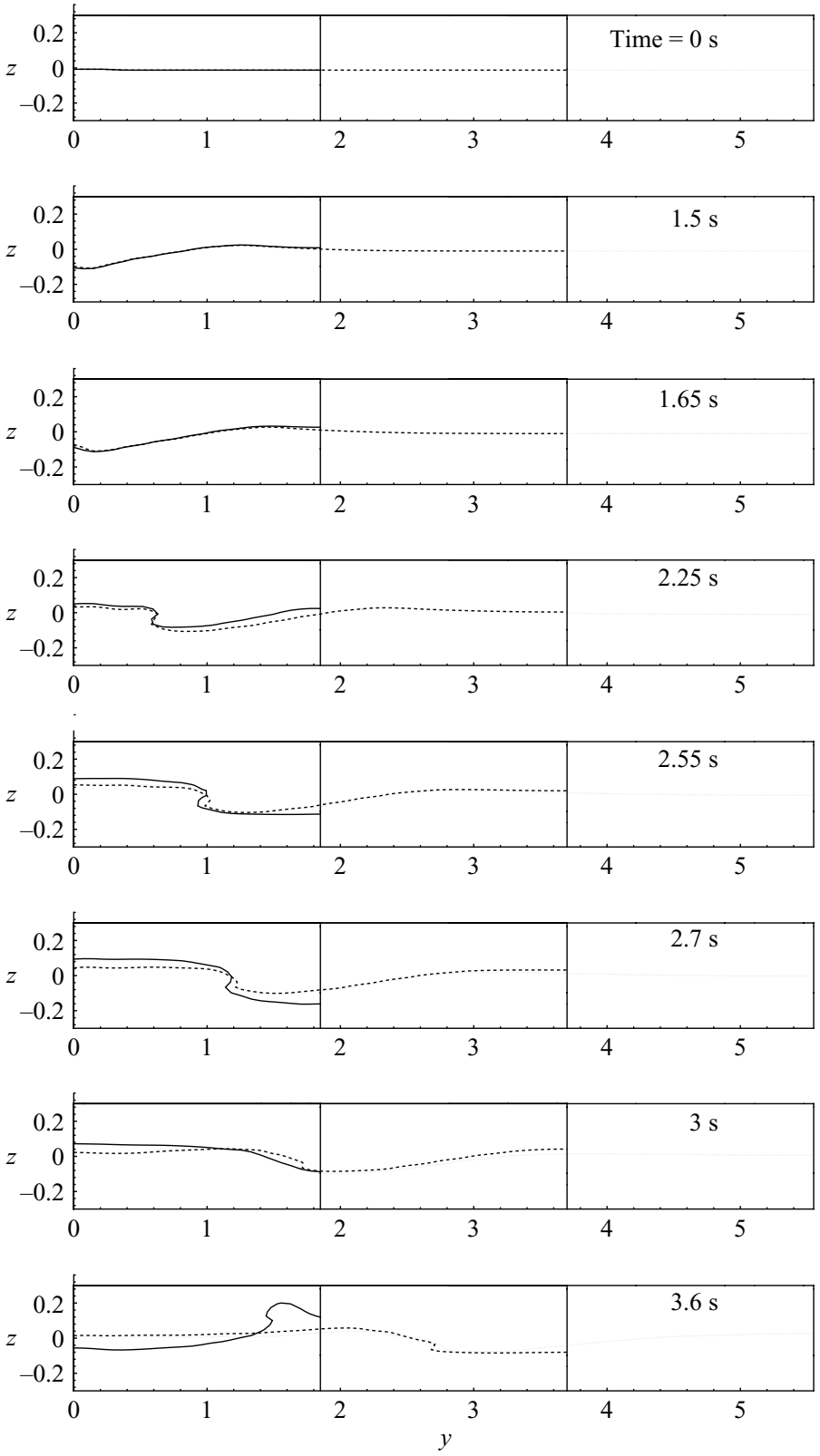

FIGURE 26. The shoreline locations at different time for different channel width. Only half the wave tank is presented. - , shoreline positions for width $3.7 \mathrm{~m} ;---$, for width $7.4 \mathrm{~m}, \ldots$, for width $11.1 \mathrm{~m}$.

From the discussions given in the previous sections, it is clear that the sidewalls have effects on the maximum runups in most of the experimental cases presented herein. To demonstrate this fact more clearly, numerical simulations for the subaerial case were repeated by using two wider wave tanks, with widths of $7.4 \mathrm{~m}$ and $11.1 \mathrm{~m}$ (i.e. the numerical wave tank width is the double and triple of the experimental tank width, respectively). We used exactly the same conditions $(\Delta=0.454 \mathrm{~m}$ and $\gamma=3.52)$ and slide displacement as given in the experiment. Several snapshots of shorelines for three simulations with different wave tank widths are shown in figure 26. 


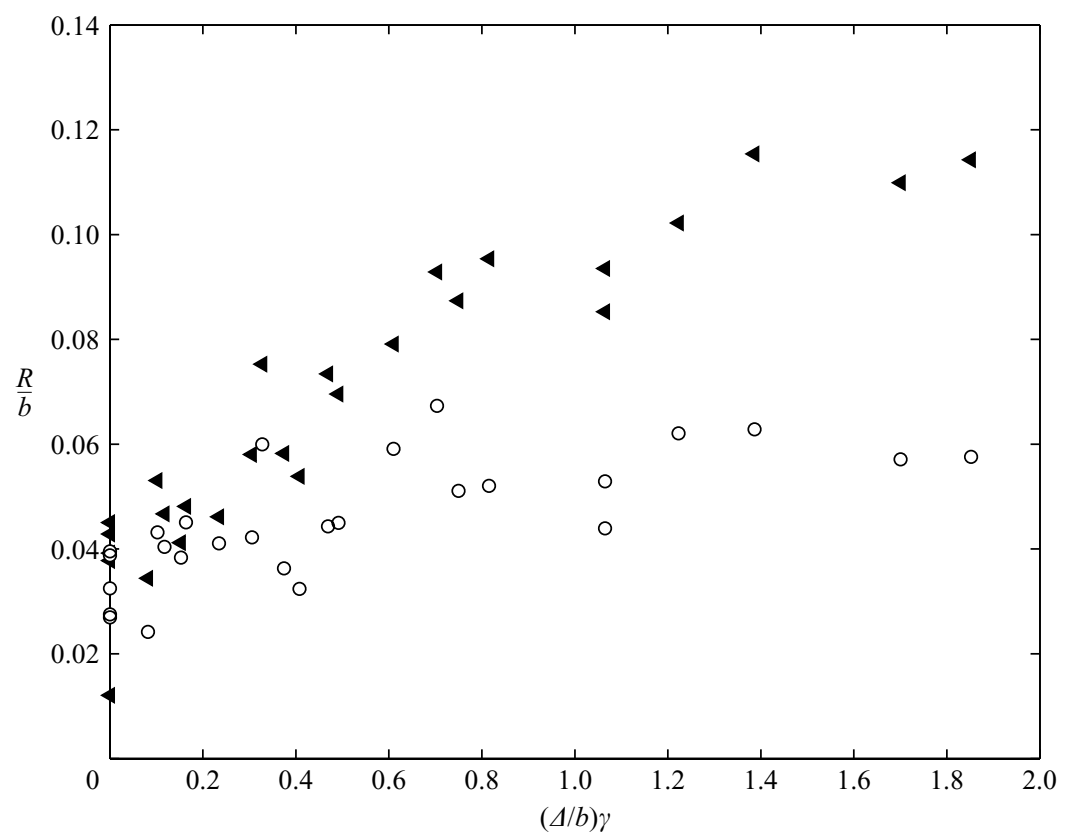

FIGURE 27. The normalized maximum runups, obtained from numerical simulations for 4 , channel width $=3.7 \mathrm{~m} ; \bigcirc, 7.4 \mathrm{~m}$, are plotted against $(\Delta / b) \gamma$ for subaerial slides.

Before time $1.5 \mathrm{~s}$, three shorelines are nearly collapsed into one, indicating that the leading seaward wave has not reached the sidewalls and the shoreline location has not been affected. At time $1.65 \mathrm{~s}$, the radiated wave has reached the sidewall in the narrowest wave tank with width $3.7 \mathrm{~m}$, and the sidewall effect makes the shoreline slightly different from those shorelines of width $7.4 \mathrm{~m}$ and width $11.1 \mathrm{~m}$. However, the shorelines of width $7.4 \mathrm{~m}$ and width $11.1 \mathrm{~m}$ are still identical, since the leading radiated wave has not reached the sidewalls of those wider tanks. From time $1.8 \mathrm{~s}$ to time $2.85 \mathrm{~s}$, two phenomena co-exist in the narrowest tank. First, the rebounding waves generate a uprush and a top-hat shaped shoreline with a sharp front moving outwardly in the alongshore direction. Secondly, the shoreline oscillates as a standing cross-wave (similar to figure 23) with wavelength, $\lambda$, equal to the tank width. The shoreline oscillations have anti-nodes at the sidewalls and the centreline. The wave period of the standing cross-wave can be estimated by using the linear dispersion relationship for edge waves on a plane slope, i.e. $T=\sqrt{2 \pi \lambda / g \sin \theta}$. Using $\lambda=3.7 \mathrm{~m}$ and $\sin \theta=1 / \sqrt{5}$, we can calculate the wave period as $T=2.3 \mathrm{~s}$. Therefore, at time $=$ $(1.55+\mathrm{T} / 2) \mathrm{s}-2.7 \mathrm{~s}$, The standing cross-wave reachesacrest along the centreline and increases the maximum runup by about $30 \%$ for this particular case. It is also evident that in the wider tank width cases, the standing cross-wave is not set up in time to affect the maximum runup. The propagating shoreline front reaches the sidewalls of the narrowest tank at time $=3.6 \mathrm{~s}$ and is reflected back from the sidewalls as shown in figure 26. This shoreline front reaches the sidewalls of wider tanks at a much later time. We remark here that the standing cross-wave features observed above are common for the subaerial case and they becomes less obvious for the submerged slide cases.

Because the tank width used in experiments could affect the maximum runups, we re-simulate most of the experiments with tank width $7.4 \mathrm{~m}$, in which the sidewall effects on the maximum runups become insignificant. Figure 27 shows the runup 


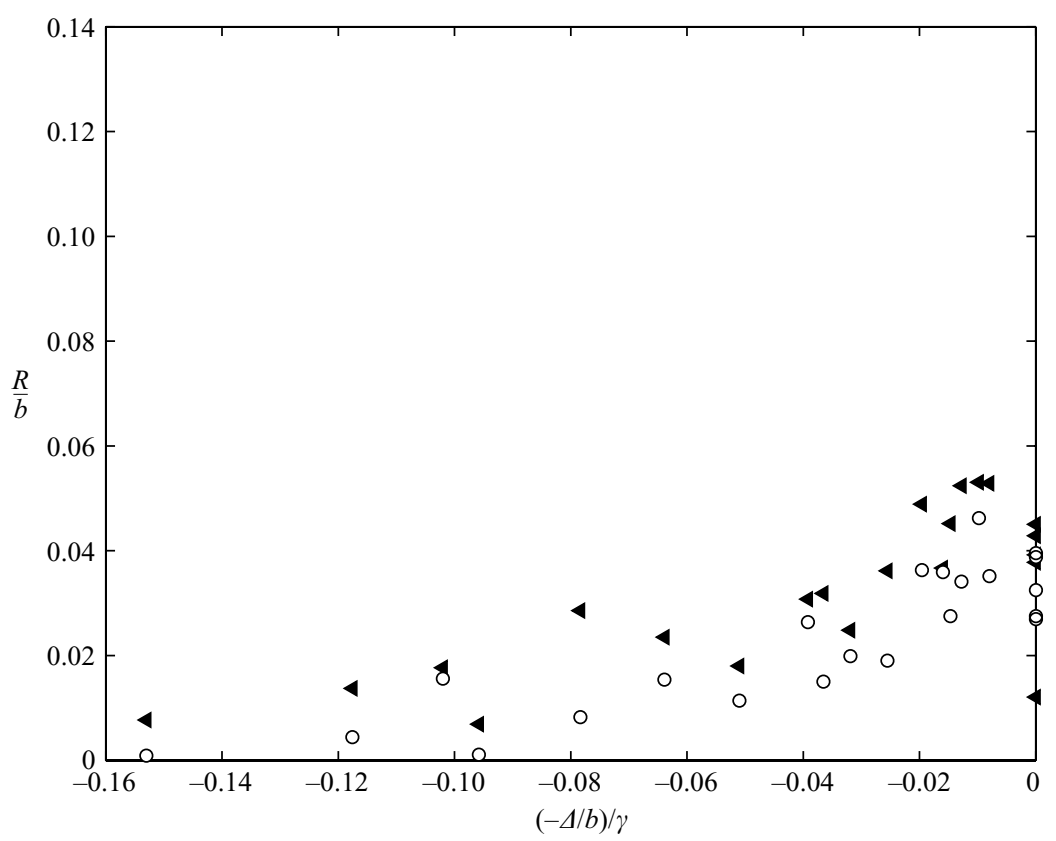

FIGURE 28. The normalized maximum runups, obtained from numerical simulations for

4 , channel width $=3.7 \mathrm{~m} ; \bigcirc, 7.4 \mathrm{~m}$, are plotted against $(\Delta / b) \gamma^{-1}$ for submerged slides.

comparisons between the numerical simulations of width $3.7 \mathrm{~m}$ and width $7.4 \mathrm{~m}$. Obviously, the maximum runups in the wide tank (without the sidewall effects) are lower than those in the experimental tank. As the initial elevation and the specific weight increase, the maximum runups reach a constant value, $R / b=0.06$. The gaps between the maximum runups in widths $3.7 \mathrm{~m}$ and $7.4 \mathrm{~m}$ are in the range from $30 \%$ to $50 \%$ of the original maximum runup heights.

\section{Concluding remarks}

An experimental and numerical investigation on the runup/rundown generated by a sliding mass is reported. The numerical simulation model is checked in detail with the experimental data for one set of experiments. The numerical results also provide a detailed description of the three-dimensional complex flows. The following major conclusions can be draw from this study:

(i) Significantly larger runup is realized for initially subaerial slides compared to submerged slides. For the slide shapes investigated, the maximum relative runup, $R / b$, was less than about 0.1 for the submerged cases and varied from about 0.1 to 0.175 for the subaerial cases.

(ii) The initial acceleration for a submerged slide is relatively constant; for a subaerial slide it increases with distance above the SWL until the slide is just completely out of the water.

(iii) For the submerged cases, the runup decreases as the submergence increases asymptotically, approaching zero as the submergence tends to infinity.

(iv) The results for the sliding hemisphere indicated larger rundown than runup for the same submergence-specific weight parameter, $(\Delta / b) \gamma$. 
(v) The runup and the rundown are controlled by size, submergence and initial motion time history.

(vi) The LES results illustrate the characteristics of the complex three-dimensional free-surface flows. Flows are strongly transient, rotational and turbulent. For the subaerial slide case shown, the maximum runup is caused by the rebounding waves, which are the results of the convergent flows above the sliding wedge.

(vii) Numerical results for the velocity field and free-surface displacement also reveal that the cross-section (on the $(y, z)$-plane) influenced by the sliding mass is roughly $1.5-2.0$ times the slide cross-section. Hence, when the depth of submergence is greater than three times the height of the slide, the slide becomes ineffective in generating waves.

(viii) The numerical results also demonstrated that the subaerial-slide-generated waves can set up a standing cross-wave, which could enhance the maximum runup from $30 \%$ to $50 \%$ for the experiments performed. For the submerged slide cases, the standing-wave pattern is less clear.

This work was supported by the Geohazards Mitigation Program of the National Science Foundation through grants to the authors. P. L.F. L. would also like to acknowledge the support from the Fluid Dynamics and Hydraulics Program and the Physical Oceanography Program of the National Science Foundation. C. E. S. would like to thank Burak Uslu and Christophe Gaudiot for their help with the experiments.

\section{REFERENCES}

Ambraseys, N. N. 1960 The seismic sea wave of July 9, 1956 in the Greek Archipelago. J. Geophys. Res. 65, 1257-1265.

Bardet, J.-P., Synolakis, C. E., Davies, H. L., Imamura, F. \& Okal, E. A. 2003 Landslide tsunamis: recent findings and research directions. Pure Appl. Geophys. 160, 1793-1809.

Bussmann, M., Kothe, D. B. \& Sicilian, J. M. 2002 Modeling high density ratio incompressible interfacial flows. Proc. FEDSM'02, 2002 ASME Fluids Engng Div. Summer Meeting. FEDSM 2002-31125, pp. 1-7.

CAвот, W. \& Moin, P. 2000 Approximate wall boundary conditions in the large-eddy simulation of high Reynolds number flow. Flow Turb. Combust. 63, 269-291.

DeArdroff, J. W. 1970 A numerical study of three-dimensional turbulent channel flow at large Reynolds numbers. J. Fluid Mech. 41, 453-480.

Dommermuth, D. G., Rottman, J. W., Innis, G. E. \& Novikov, E. A. 2002 Numerical simulation of the wake of a towed sphere in a weakly stratified fluid. J. Fluid Mech. 473, 83-101.

Eissler, H. K. \& Kanamori, H. 1987 A single-force model for the 1975 Kalapana, Hawaii, earthquake. J. Geoph. Res. Solid Earth 92, 4827-4836.

Fryer, G., Watts, P. \& Pratson, L. 2004 Source of the great tsunami of 1 April 1946: a landslide in the upper Aleutian forearc. Mar. Geo. 203, 201-218.

Grilli, S. T., WatTs, P. \& Dias, F. 2001 Numerical and experimental modelling of tsunamis generated by underwater landslides. Euro. Geophys. Soc. 26th General Assembly, Nice, France.

Gutenberg, B. 1939 Tsunamis and earthquakes. Bull Seismol. Soc. Am. 29, 517-526.

Hasegawa, H. S. \& Kanamori, H. 1987 Source mechanism of the magnitude 7.2 Grand Banks Earthquake of November 1929: double couple or submarine landslide? Bull. Seismol. Soc. Am. 77, 1984-2004.

HeInRICH, P. 1991 Nonlinear numerical model of landslide-generated water waves. Intl J. Engng Fluid Mech. 4, 403-416.

HeINRICH, P. 1992 Nonlinear water waves generated by submarine and aerial landslides. J. Waterway Port Coastal Ocean Engng 118, 249-266. 
Hendrikson, K., Shen, L., Yue, D. K. P., Dommermuth, D. G. \& Adams, P. 2003 Simulation of steep breaking waves and spray sheets around a ship: the last frontier in computational ship hydrodynamics. Resource Newslett. US Army Engineer Research and Development Centre Information Technology Laboratory, Fall, pp. 2-7.

HiRT, C. W. \& Nichols, B. D. 1981 Volume of fluid method for the dynamics of free boundaries. J. Comput. Phys. 39, 201-225.

JiAng, L. \& LEBLOND, P. H. 1992 The coupling of a submarine slide and the surface waves which it generates. J. Geoph. Res. Oceans 97 (C8), 12 731-12 744.

Kanamori, H. 1985 Non-double-couple seismic source (abstact). Proc. of the 23rd General Assembly Intl Assoc. of Seismological Physics Earth International Tokyo, p. 425.

Kawata, Y., Borrero, J., Davies, H. et al. 1999 Tsunami in Papua New Guinea was as intense as first thought. EOS, Trans. Am. Geophys. Union 80, 101, 104-105.

Kothe, D. B., Williams, M. W., Lam, K. L., Korzewa, D. R., Tubesing, P. K. \& Puckett, E. G. 1999 A second-order accurate, linearity-preserving volume tracking algorithm, for free surface flows on 3-D unstructured meshes. Proc. 3rd ASME/JSME Joint Fluids Engng Conf. 18-22 July. FEDSM99-7109.

LiN, P. \& LI, C. W. 2003 Wave-current interaction with a vertical square cylinder. Ocean Engng 30, 855-876.

Liu, P. L-F., Lynnet, P. \& Synolakis, C. E. 2003 Analytical solutions for forced long waves on a sloping beach. J. Fluid. Mech. 478, 101-109.

Murty, T. S. 1979 Submarine slide waves in Kitimat Inlet, BC. J. Geoph. Res. 84(C12), 7777-7779.

OKaL, E. A. 1992 Use of the mantle magnitude for reassessment of the seismic moment of historical earthquakes. I: Shallow events. Pure Appl. Geophys. 139, 17-57.

OKal, E. A. 2003 T-waves from the 1998 Papua New Guinea Earthquake and its aftershocks: timing the tsunamigenic slump. Pure Appl. Geophys. 160, 1843-1863.

Okal, E. A., Plafker, G., Synolakis, C. E. \& Borrero, J. C. 2003 Near field survey of the 1946 Aleutian tsunami on Unimak and Senak islands. Bull. Seismol. Soc. Am. 93, 1226-1234.

Okal, E. A., Synolakis, C. E., Fryer, G. J., Heinrich, P., Borrero, J. C., Ruscher, C., Arcas, D., Guille, G. \& Rousseau, D. 2002 A field survey of the 1946 tsunami in the far field. Seismol. Res. Lett. 73, 490-503.

Pelinovsky, E. \& Poplavsky, A. 1996 Simplified model of tsunami generation by submarine landslides. Phys. Chem. Earth. 21 (12), 13-17.

Rider, W. J. \& Kothe, D. B. 1998 Reconstructing volume tracking. J. Comput. Phys. 141, 112-152.

Shen, L. \& YuE, D. K. P. 2001 Large-eddy simulation of free-surface turbulence. J. Fluid Mech. 440, 75-116.

SMAGORINSKY, J. 1963 General circulation experiments with the primitive equations: I. The basic equations. Mon. Weather Rev. 91, 99-164.

Stirem, H. L. \& Miloh, T. 1975 Tsunamis induced by submarine slumping off the coast of Israel. Israel Atomic Energy Commission.

SynolaKis, C. E. 2003 Tsunamis and seiches. In Earthquake Engineering Handbook (ed. W.-F. Chen \& C. Scawthorn), pp. 9-1-9-90. CRC Press.

Synolakis, C. E., Bardet, J. P., Borrero, J. C., Davies, H., Okal, E. A., Silver, E. A., Sweet, S. \& Tappin, D. R. 2002 Slump origin of the 1998 Papua New Guinea Tsunami. Proc. R. Soc. Lond. A, 458, 763-789.

Synolakis, C. E., Liu, P. L.-F., Yeh, H. \& Carrier, G. 1997 Tsunamigenic seafloor deformations. Science 278, 598-600.

YuK, D., YIM, S. \& LiU, P. L.-F. 2003 Numerical modelling of submarine mass movement generated waves using the RANS model. In Submarine Mass Movements and Their Consequences. (ed. J. Locat \& J. Mienert), pp. 183-193, Kluwer.

Ward, S. N. 2001 Landslide tsunami. J. Geophys. Res. 106, 1865-1878.

WatTs, P. 1997 Water waves generated by underwater landslides. PhD thesis, California Institute of Technology.

WIEGEL, R. L. 1955 Laboratory studies of gravity waves generated by the movement of a submerged body. Trans. Am. Geophys. Union 36, 5.

Wu, T.-R. 2004 A numerical study of three-dimensional breaking waves and turbulence effects. $\mathrm{PhD}$ thesis, Cornell University. 